\title{
Induction/reversal of drug resistance in gastric cancer by non-coding RNAs (Review)
}

\author{
CHAO CHEN, XIAOHUAN TANG, YUANDA LIU, JIAMING ZHU* and JINGJING LIU* \\ Department of Gastrointestinal Nutrition and Hernia Surgery, The Second Hospital of Jilin University, \\ Changchun, Jilin 130041, P.R. China
}

Received December 18, 2018; Accepted February 21, 2019

DOI: 10.3892/ijo.2019.4751

\begin{abstract}
Gastric cancer (GC) is one of the most prevalent and malignant types of cancer worldwide. In China, it is the second most common type of cancer and the malignancy with the highest incidence and mortality rate. Chemotherapy for GC is not always effective due to the development of drug resistance. Drug resistance, which is frequently observed in GC, undermines the success rate of chemotherapy and the survival of patients with GC. The dysregulation of non-coding RNAs (ncRNAs), primarily microRNAs (miRNAs or miRs) and long non-coding RNAs (lncRNAs), is involved in the development of GC drug resistance via numerous mechanisms. These mechanisms contribute to the involvement of a large and complex network of ncRNAs in drug resistance. In this review, we focus on and summarize the latest research on the specific mechanisms of action of miRNAs and lncRNAs that modulate drug resistance in GC. In addition, we discuss future prospects and clinical applications of ncRNAs as potential targeted therapies against the chemoresistance of GC.
\end{abstract}

\section{Contents}

1. Introduction

2. Multi-drug resistance and single drug resistance

3. Non-coding RNAs related to multi-drug resistance in gastric cancer

4. Non-coding RNAs related to single drug resistance in gastric cancer

5. Conclusions and future directions

Correspondence to: Professor Jiaming Zhu or Dr Jingjing Liu, Department of Gastrointestinal Nutrition and Hernia Surgery, The Second Hospital of Jilin University, 218 Ziqiang Street, Changchun, Jilin 130041, P.R. China

E-mail: zhujiaming75@sina.com

E-mail: jingjingstarone@163.com

*Contributed equally

Key words: non-coding RNA, microRNA, long non-coding RNA, drug resistance, gastric cancer

\section{Introduction}

Gastric cancer (GC) is one of the most common malignant types of cancer and the third leading cause of cancer-related death worldwide in the last two decades (1). In many Asian countries, particularly in China, GC is the second most common type of cancer and the leading malignancy as regards the incidence and mortality rate (2). Although advances in surgical techniques have improved the prognosis of patients with early-stage GC, the majority of patients are diagnosed at the advanced stages of the disease and thus have to undergo chemotherapy and radiotherapy (3). However, the 5 -year-survival rate has not improved significantly due to the development of chemoresistance to anti-cancer drugs (4). Drug resistance, which is frequently observed in GC, threatens the success rate of chemotherapy and the survival of patients with GC. The underlying mechanisms of drug resistance remain to be fully understood (5-7). One well-known mechanism is the modulation of the epithelial-mesenchymal transition (EMT) process which converts epithelial cells to mesenchymal cells. Studies have confirmed that EMT can induce drug resistance by decelerating the proliferation rate of cancer cells, upregulating the expression of ATP binding cassette (ABC) transporters which mediate drug efflux, and increasing the expression of anti-apoptotic proteins (8-10). It has also been demonstrated that EMT can reconstruct the tumor microenvironment, thereby inducing resistance to immunotherapies (11). Another well-known mechanism related to drug resistance is cancer stem cells (CSCs). CSCs are a cell population with high tumorigenic potential in tumors, and these cells modulate cancer initiation, development and metastasis (12-14). Extensive studies have indicated that CSCs induce drug resistance by expelling intracellular therapeutic drugs to the extracellular space through transport proteins (15-17). A high aldehyde dehydrogenase (ALDH) activity is another element related to drug resistance in CSCs $(18,19)$. Beyond EMT and CSCs, a number of studies have indicated a close association between non-coding RNAs (ncRNAs) and drug resistance in GC, a possibility that has received substantial research attention.

ncRNAs are a type of RNA that does not encode proteins, and they are associated with cell development, metastasis, invasion, proliferation and apoptosis (20). ncRNAs are thought to be involved in drug resistance in human GC (21). Among 
ncRNAs, microRNAs (miRNAs or miRs) and long non-coding RNAs (lncRNAs), two main families of ncRNAs, play a role in cancer drug resistance (22). miRNAs are approximately 19-25 nucleotides in length and can bind to the 3'-untranslated region (3'-UTR) of target genes to regulate their expression (23). Studies have analyzed the association between miRNAs and drug resistance in GC $(21,24,25)$. IncRNAs are $>200$ nucleotides in length and are always transcribed by RNA polymerase II, and they lack opening reading frames (ORFs) $(26,27)$. lncRNAs exert their effects by interacting with DNA, RNA and protein (28). Several studies have investigated the function of lncRNAs in drug resistance in GC $(21,28,29)$. In this review, we summarize the mechanisms underlying the role of miRNAs and lncRNAs in regulating drug resistance in GC.

\section{Multi-drug resistance and single drug resistance}

Over the past decades, several chemotherapeutic regimens based on different anti-cancer drugs have improved the survival of a multitude of patients GC. However, chemotherapy in patients with GC often fails due to the development of multi-drug resistance (MDR) and single drug resistance (30-32). Both MDR and single drug resistance in GC are regulated by complex mechanisms, including some classic approaches (Fig. 1). One mechanism of MDR is the modulation of apoptosis and autophagy in cancer cells induced by anti-cancer drugs (25). For example, miR-218 has been shown to inhibit drug-induced apoptosis by increasing the expression of $\mathrm{Bcl}-2$-associated $\mathrm{X}$ protein (Bax) and decreasing the expression of B-cell lymphoma-2 (Bcl-2) (33). miR-23b-3p targets autophagy-related gene 12 (ATG12) and high mobility group box 2 (HMGB2) to prevent autophagy and increase the sensitivity of GC cells to 5-fluorouracil (5-FU), vincristine (VCR) and cisplatin (DDP/CDDP) (34). Another important mechanism leading to MDR is the induction of drug efflux in cancer cells by increasing specific energy-dependent transporters, such as P-glycoprotein 1 (P-gp; also known as ABCB1) (25). For instance, miR-106a expedites the efflux of adriamycin (ADR/ADM) to promote ADR resistance in GC by targeting runt-related transcription factor 3 (RUNX3) directly (35). Other mechanisms that may lead to drug resistance have been reported, including DNA damage repair, the mutation of drug targets and the modification of stem cells among others (36-43).

In addition to these ncRNAs that lead to MDR, there are other ncRNAs that are related to the chemosensitivity of single anti-cancer drugs in GC, including DDP, 5-FU, and VCR. Although some of these ncRNAs play roles in more than one type of drug resistance, the identification of ncRNAs related to single drug resistance is an area worth exploring to promote the development of more effective chemotherapeutic drugs for the treatment of GC.

\section{Non-coding RNAs related to multi-drug resistance in gastric cancer}

Dysregulated miRNAs. In recent years, several studies have focused on the association between miRNAs and MDR in GC. A number of miRNAs are involved in drug sensitivity in GC via common mechanisms such as apoptosis, the mammalian target of rapamycin (mTOR) pathway and the EMT pathway. miR-185 has been shown to be downregulated in GC and to be related to the resistance to multiple drugs such as ADR, 5-FU, oxaliplatin (L-OHP/OXA), doxorubicin (DOX) and CDDP through the regulation of zinc finger protein 139 (ZNF139) and apoptosis repressor $(44,45)$. miR-218 targets smoothened (SMO) directly to reverse the drug resistance of GC cells to ADM, L-OHP and 5-FU (33). It has been demonstrated that miR-218 is upregulated in patients with GC undergoing cytoreductive surgery (CRS) and hyperthermic intraperitoneal chemotherapy (HIPEC), and it targets mTOR to promote the chemosensitivity of GC cells to CDDP in vitro (46). Zeng et al demonstrated that miR-145 targets the 3'-UTR of CD44 directly to promote chemosensitivity to 5-FU and DDP in GC (47). miR-101 enhances the sensitivity to DDP or VCR by regulating Annexin A2 (ANXA2) and vascular endothelial growth factor (VEGF)-C negatively to inhibit viability and promote apoptosis of GC cells $(48,49)$. miR-495 targets the multi-drug resistance protein $1(M D R l)$ gene to enhance the sensitivity of GC cells to paclitaxel (PTX) and DOX (50). By targeting enhancer of zeste homolog 2 (EZH2) directly, miR-126 increases the sensitivity of GC cells to VCR and ADR (51). Shang et al demonstrated that miR-508-5p targets $\mathrm{ABCB} 1$ and Zinc ribbon domain-containing 1 (ZNRD1) directly to regulate the MDR of GC cells (52). In addition, the upregulation of miR-27b has been shown to promote miR-508-5p expression via cyclin G1 (CCNG1) and p53 in GC cells, enhancing the sensitivity to chemotherapeutic agents, such as ADR, VCR, 5-FU and CDDP (53). Other miRNAs, including miR-30a $(30,54,55)$, miR-107 (56), miR-BART20-5p (57), miR-23b-3p (34) and miR-129-5p (58) have been shown to promote chemotherapeutic sensitivity in GC, and these miRNAs and the brief mechanisms are presented in Table I.

NumerousmiRNAs haveopposite functions in MDR through classical signaling pathways, such as the phosphoinositide 3-kinase (PI3K)/protein kinase B (PKB/Akt) and nuclear factor $\kappa$-light-chain-enhancer of activated $\mathrm{B}$ cells $(\mathrm{NF}-\kappa \mathrm{B})$ pathways $(59,60)$. miR-20a is an important upregulated miRNA in GC (59-62). Zhou et al reported that miR-20a not only decreased the sensitivity of GC cells to VCR, ADR, 5-FU and CDDP by directly targeting leucine-rich repeats and immunoglobulin-like domains 1 (LRIG1), but also affected the mitogen-activated protein kinase (MAPK)/extracellular signal-regulated kinase (ERK) and PI3K/Akt signaling pathways, which are mediated by epidermal growth factor receptor (EGFR) to regulate GC cell MDR (59). Other studies have indicated that miR-20a inhibits the expression of cylindromatosis (CYLD) and NFKBIB (also known as $\mathrm{I} \kappa \mathrm{B} \beta$ ), activating the $\mathrm{NF}-\kappa \mathrm{B}$ pathway and two downstream targets, livin and survivin, to promote GC chemoresistance to $\operatorname{DDP}(60,61)$. Another study indicated that miR-20a enhanced the resistance of GC cells to docetaxel (DOC) (62). miR-363 has been reported to target F-box and WD repeat domain-containing 7 (FBW7) directly to reduce the sensitivity of GC cells to the DOC + DDP + 5-FU (DCF) regimen (63). miR-106a promotes ADR and DDP resistance in GC cells by expediting the efflux of ADR, targeting RUNX3 to inhibit apoptosis induced by ADR, and modulating phosphatase and tensin homologue (PTEN) and its downstream PI3K/Akt 


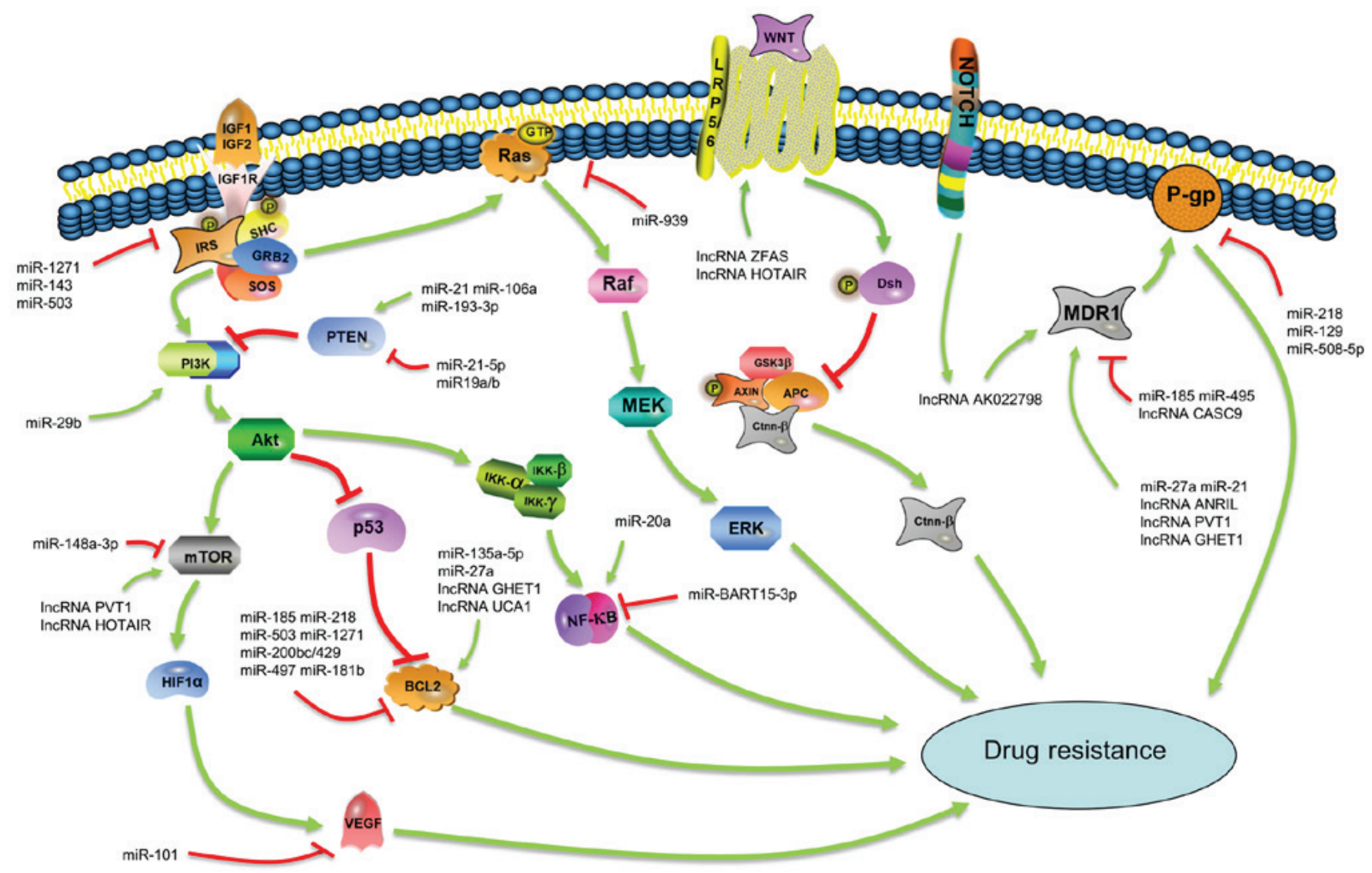

Figure 1. Classic mechanisms involved in drug resistance in gastric cancer. miRNAs and lncRNAs modulate drug resistance in gastric cancer through classic pathways, such as the PTEN/PI3K/Akt, IGF1R/IRS1, MDR1/P-gp, Wnt/ $\beta$-catenin, MAPK/ERK, NF- $\kappa$ B and Bcl-2/Bax pathways, which contribute to a complex regulatory network. The arrows represent activation effect and the T symbols indicate inhibition effect. miRNAs, microRNAs; lncRNAs, long non-coding RNAs; IGF1, insulin-like growth factor 1; IGF2, insulin-like growth factor 2; IGF1R, insulin-like growth factor 1 receptor; SHC, SH2 containing protein; GRB2, growth factor receptor-bound protein 2; SOS, son of sevenless; PI3K, phosphoinositide 3-kinase; Akt, protein kinase B; mTOR, mammalian target of rapamycin; HIF1 $\alpha$, hypoxia-inducible factor $1 \alpha$; Iкк, IкB kinase; Dsh, dishevelled; GSK3 $\beta$, glycogen synthase kinase $3 \beta$; AXIN, axis inhibitor; APC, adenomatous polyposis coli; ctnn- $\beta$, $\beta$-catenin; P-gp, P-glycoprotein 1.

signaling pathway $(35,64)$. miR-20b, miR-27a and miR-181a have been shown to enhance the resistance of GC cells to epirubicin/oxaliplatin/capecitabine (EOX) by targeting hypoxia inducible factor-1 (HIF1A/HIF-1 $\alpha$ ), MDR1 and homeodomain-interacting protein kinase-2 (HIPK2) (65). miR-27a, which acts as a biomarker to predict 5-FU-based chemotherapy responses in GC, induces resistance to ADR in GC cells via P-gp, cyclin D1 and p21, and it is inhibited by upstream HIF-1 $\alpha$ to suppress MDR1/P-gp, lipoprotein receptor-related protein (LRP) and $\mathrm{Bcl}-2$ to reduce L-OHP resistance (66-68). miR-223 negatively regulates the expression of F-box and WD repeat domain-containing 7 (FBXW7) to influence cell cycle progression in DDP-resistant cells, thereby modulating DDP resistance, and its overexpression in HER2-positive GC cells inhibits FBXW7 expression and enhances the resistance to trastuzumab (TZ) by preventing TZ-induced apoptosis $(69,70)$. miR-21 enhances the resistance to several drugs, such as DDP, PTX and TZ by targeting PTEN, the PI3K/Akt signaling pathway and P-gp (71-73). miRNAs involved in MDR in GC are summarized in Table II.

The role of dysregulated miRNAs in MDR in GC cells is mediated by numerous regulatory mechanisms, including the $\mathrm{ABCB} 1 / \mathrm{MDR} 1 / \mathrm{P}$-gp pathway, apoptosis induced by $\mathrm{Bcl}-2$ family proteins, cell autophagy and the EMT process. By regulating these dysregulated miRNAs, the drug resistance of GC to chemotherapy may be reversed, and this may provide some novel ideas for the treatment of GC.

Dysregulated long non-coding RNAs. Over the past decades, studies have indicated that lncRNAs play significant roles in the biological behaviors of GC cells, such as carcinogenesis, development, proliferation, invasion and metastasis, as well as chemosensitivity and drug resistance $(21,74)$. To provide new directions for the research of MDR in GC cells, in this review, we focus on the complex molecular mechanisms underlying anti-cancer drug resistance modulated by various IncRNAs (Table III).

Shang et al reported that IncRNA CASC9 downregulated the expression of MDR1 to reverse the MDR of GC cells to PTX and ADR (75). Wang et al reported that lncRNA MRUL increased the expression of $\mathrm{ABCB} 1$ to enhance the sensitivity of GC cells to ADR and VCR and suppress the MDR phenotype (76). Xu et al demonstrated that IncRNA ZFAS, whose expression was upregulated in GC cells, enhanced DDP and PTX resistance in SGC7901 cells by modulating the Wnt/ $\beta$-catenin signaling pathway (77). IncRNA MALAT1 competes with miR-23b-3p to promote the expression of ATG12 and enhance the resistance to VCR and DDP (78). The 
Table I. miRNAs which reverse multi-drug resistance in gastric cancer.

\begin{tabular}{lllll}
\hline & & Effect on drug & & \\
MicroRNA & Dysregulation & resistance & \multicolumn{1}{c}{ Corresponding drugs } & \multicolumn{1}{c}{ Pathway/target } \\
\hline miR-185 & $\downarrow$ & Reversing & ADR, 5-FU, OXA; DOX, DDP & $\begin{array}{l}\text { MDR1/P-gp, MRP, Bcl-2; } \\
\text { ARC/RUNX3 }\end{array}$ \\
miR-218 & $\downarrow$ & Reversing & ADR, OXA, 5-FU & SMO/P-gp/Bax/Bcl2 \\
miR-145 & $\downarrow$ & Reversing & 5-FU, DDP & CD44 \\
miR-101 & $\downarrow$ & Reversing & DDP, VCR & ANXA2; VEGF-C \\
miR-495 & $\downarrow$ & Reversing & PTX, DOX & MDR1/ABCB1 \\
miR-126 & $\downarrow$ & Reversing & ADR, VCR & EZH2 \\
miR-508-5p & $\downarrow$ & Reversing & & ABCB1/ZNRD1 \\
miR-27b & $\downarrow$ & Reversing & ADR, VCR, 5-FU, DDP & CCNG1/P53/miR-508-5p \\
miR-30a & $\downarrow$ & Reversing & DDP, 5-FU & EMT \\
miR-107 & $\downarrow$ & Reversing & OXA, PTX, ADR, 5-FU & Lin28 \\
miR-BART20-5p & $\downarrow$ & Reversing & 5-FU, docetaxel & (53) \\
miR-23b-3p & $\downarrow$ & Reversing & 5-FU, VCR, DDP & BAD \\
miR-129-5p & $\downarrow$ & Reversing & VCR, ADR & ATG12/HMGB2/autophagy \\
\hline
\end{tabular}

ADR, adriamycin; 5-FU, 5-fluorouracil; OXA, oxaliplatin; DOX, doxorubicin; DDP, cisplatin; VCR, vincristine; PTX, paclitaxel; MDR1, multidrug resistance protein 1; P-gp/ABCB1, P-glycoprotein 1; MRP, multi-drug resistance-associated protein; Bcl-2, B-cell lymphoma-2; ARC, apoptosis repressor with caspase recruitment domain; RUNX3, runt-related transcription factor 3; SMO, smoothened; Bax, Bcl-2-associated X protein; ANXA2, Annexin A2; VEGF-C, vascular endothelial growth factor C; EZH2, Enhancer of Zeste Homolog 2; ZNRD1, Zinc ribbon domain-containing 1; EMT, epithelial-mesenchymal transition; BAD, Bcl-2-associated death promoter; ATG12, autophagy-related gene 12; HMGB2, high mobility group box 2;ABCC5, multi-drug resistance-associated protein 5; ABCG1, ATP-binding cassette sub-family G member $1 ;$ /, not mentioned; $\downarrow$, downregulation.

Table II. miRNAs inducing multi-drug resistance in gastric cancer.

\begin{tabular}{|c|c|c|c|c|c|}
\hline MicroRNA & Dysregulation & $\begin{array}{l}\text { Effect on drug } \\
\text { resistance }\end{array}$ & $\begin{array}{l}\text { Corresponding } \\
\text { drugs }\end{array}$ & Pathway/target & Refs. \\
\hline miR-20a & $\uparrow$ & Inducing & $\begin{array}{l}\text { VCR, ADR, 5-FU, } \\
\text { DDP; docetaxel }\end{array}$ & 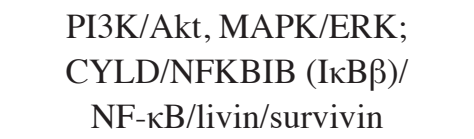 & $(59-62)$ \\
\hline $\operatorname{miR}-363$ & $\uparrow$ & Inducing & $\begin{array}{l}\text { DCF (docetaxel+ } \\
\text { DDP+5-FU) }\end{array}$ & FBXW7 & $(63)$ \\
\hline miR-106a & $\uparrow$ & Inducing & DDP, ADR & RUNX3 & $(35,64)$ \\
\hline $\operatorname{miR}-20 b / 27 a / 181 a$ & l & Inducing & $\mathrm{EOX}$ & HIF1A/MDR1/HIPK2/hypoxia & $(65)$ \\
\hline $\operatorname{miR}-27 a$ & $\uparrow$ & Inducing & VCR, PTX & $\begin{array}{c}\text { P-gp, cyclin D1, p21; } \\
\text { HIF-1 } \alpha / \text { MDR1/P-gp/LRP/Bcl-2 }\end{array}$ & $(66-68)$ \\
\hline $\operatorname{miR}-223$ & $\uparrow$ & Inducing & DDP, TZ & FBXW7/apoptosis & $(69,70)$ \\
\hline $\operatorname{miR}-21$ & $\uparrow$ & Inducing & DDP, PTX, TZ & $\begin{array}{l}\text { PTEN, PI3K/Akt } \\
\text { pathway; P-gp }\end{array}$ & $(71-73)$ \\
\hline
\end{tabular}

VCR, vincristine; ADR, Adriamycin; 5-FU, 5-fluorouracil; DDP, cisplatin; OXA, oxaliplatin; EOX, epirubicin + OXA + capecitabine; PTX, paclitaxel; TZ, trastuzumab; PI3K, phosphoinositide 3-kinase; Akt, protein kinase B; MAPK, mitogen-activated protein kinase; ERK, extracellular signal-regulated kinase; CYLD, cylindromatosis; NF- $\mathrm{B}$, nuclear factor $\kappa$-light-chain-enhancer of activated B cells; FBXW7, F-box and WD repeat domain-containing 7; RUNX3, runt-related transcription factor 3; HIF1A/HIF-1 $\alpha$, hypoxia inducible factor-1; MDR1, multi-drug resistance protein 1; HIPK2, homeodomain-interacting protein kinase-2; LRP, lipoprotein receptor-related protein; PTEN, phosphatase and tensin homologue; /, not mentioned; $\uparrow$, upregulation.

overexpression of IncRNA UCA1, which negatively correlates with miR-27b expression, enhances drug resistance to ADR, DDP and 5-FU by inhibiting miR-27b and Bcl-2 and inducing cleaved caspase-3 (79). Another study demonstrated that the downregulation of 1ncRNA UCA1 promoted the sensitivity of SGC7901/ADR cells to ADR by inducing cleaved Poly 
Table III. lncRNAs involved in multi-drug resistance in gastric cancer.

\begin{tabular}{|c|c|c|c|c|c|}
\hline lncRNA & $\begin{array}{l}\text { Expression } \\
\text { in GC }\end{array}$ & $\begin{array}{l}\text { Effect on drug } \\
\text { resistance }\end{array}$ & Drugs & Mechanism & Refs. \\
\hline CASC9 & $\uparrow$ & Reversing & PTX; ADR & Targeting MDR1 & $(75)$ \\
\hline MRUL & $\uparrow$ & Reversing & ADR; VCR & Targeting ABCB 1 & (76) \\
\hline ZFAS & $\uparrow$ & Inducing & DDP; PTX & Modulating Wnt/ $\beta$-catenin pathway & (77) \\
\hline MALAT1 & $\uparrow$ & Inducing & VCR, DDP & Targeting miR-23b-3p and ATG12 & (78) \\
\hline UCA1 & $\uparrow$ & Inducing & ADR, DDP, 5-FU & $\begin{array}{l}\text { Targeting } \mathrm{miR}-27 \mathrm{~b} / \mathrm{Bcl}-2 / \text { caspase-3 and } \\
\text { cleaved PARP/Bcl2/apoptosis pathway }\end{array}$ & $(79,80)$ \\
\hline ANRIL & $\uparrow$ & Inducing & DDP; 5-FU & Targeting MDR1 and MRP1 & $(81)$ \\
\hline
\end{tabular}

PTX, paclitaxel; ADR, adriamycin; VCR, vincristine; DDP, cisplatin; 5-FU, 5-fluorouracil; MDR1, multi-drug resistance protein 1; ABCB1, P-glycoprotein 1; ATG12, autophagy-related gene 12; Bcl-2, B-cell lymphoma-2; PARP, poly ADP-ribose polymerase; MRP1, multidrug resistance-associated protein $1 ; \uparrow$, upregulation.

ADP-ribose polymerase (PARP) and inhibiting Bcl-2 (80). IncRNA ANRIL is upregulated both in BGC823/DDP and BGC823/5-FU cells, and the silencing of 1ncRNA ANRIL reverses MDR in GC cells by targeting MDR1 and multi-drug resistance-associated protein 1 (MRP1) (81).

In summary, lncRNAs modulate the MDR of GC cells through various mechanisms, such as the Wnt/ $\beta$-catenin signaling pathway, the MDR1/MRP1 pathway, Bcl-2/caspase-3 induced apoptosis and by acting as competitive endogenous RNA (ceRNA). Notably, these reports suggest that the dysregulation of all lncRNAs involved in MDR in GC consists of upregulation, and no downregulated lncRNAs leading to MDR in GC cells have been identified to date, at least to the best of our knowledge.

\section{Non-coding RNAs related to single drug resistance in gastric cancer}

Cisplatin. DDP/CDDP is an anti-cancer agent that can destroy the target DNA of tumor cells (82). It is one of the most widely used first-line anti-cancer agents in clinical therapy, and CDDP resistance, which often occurs in GC, can result in therapeutic failure (83). Chemoresistance has attracted the attention of scientists, and many complex molecular mechanisms of DDP resistance in GC cells have been elucidated to date.

miRNAs can increase the chemosensitivity of GC cells to anti-cancer drugs. For example, the overexpression of miR-125b has been shown to enhance the chemosensitivity to DDP in GC by targeting human epidermal growth factor receptor-2 (HER2) (84). Wang and Ji found that miR-17-5p targeted p21 to modulate apoptosis caused by DDP in GC, and the downregulation of miR-17-5p enhanced the sensitivity of GC cells to DDP (85). miR-22 upregulates the expression of the glycolytic enzyme enolase1 (ENO1) by targeting its 3'-UTR to attenuate the DDP resistance of GC cells (86). miR-129 decreases the expression of P-gp to abate the resistance of GC cells to CDDP (87). The overexpression of miR-148a-3p reduces the resistance of GC cells to CDDP by inducing mitochondrial fission and downregulating A-kinase anchoring protein 1 (AKAP1), preventing cyto-protective autophagy by decreasing Ras-related protein Rab-12 (RAB12) expression and mTOR1 activation (88). AKAP1 inhibits dynamin-related protein 1 (DRP1) dephosphorylation, which is mediated by $\mathrm{p} 53$, to enhance CDDP resistance (88). miR-320a targets a disintegrin and metalloproteinase domain-containing protein 10 (ADAM10) directly to abate the sensitivity of GC cells to CDDP (89). The overexpression of miR-181a prevents the autophagy of GC cells and enhances the sensitivity of GC cells to CDDP by targeting autophagy related 5 (ATG5) (90). Other miRNAs that enhance the chemosensitivity of DDP in GC include miR-203 (91), miR-149 (92), miR-143 (93), miR-26a (94), miR-1271 (95) and miR-503 (96). These miRNAs and a brief description of their mechanisms are presented in Table IV.

Certain miRNAs exert opposite effects on chemosensitivity in DDP-resistant GC cells. miR-25 has been shown to decrease the sensitivity of GC cells to cisplatin by targeting forkhead box O3a (FOXO3a) directly (97). The chemoresistance of GC to DDP induced by miR-214 is reversed by exosomes, which act as nanoparticles (98). A low expression of miR-99a and miR-491 enhances the sensitivity of GC cells to cisplatin by targeting calpain small subunit 1 (CAPNS1)/calpain1/calpain2/caspase-3/PARP1 signaling pathway directly (83). miR-493 prevents Dickkopf-1 (DKK1) expression to enhance the CDDP resistance of GC cells (99). The expression level of miR-421 in GC cells is upregulated by HIF-1 $\alpha$ and it promotes DDP resistance through E-cadherin and caspase-3 (100). miR-29b promotes cisplatin resistance in GC cells through the PI3K/Akt signaling pathway (101). miR-141 overexpression inhibits the expression of Kelch-like ECH-associated protein 1 (KEAP1) and promotes the cisplatin resistance of SGC7901/DDP cells (102). Other miRNAs, such as miR-132 (103), miR-524-5p (104), miR-34a (105) and miR-200c (106-108) also promote resistance to DDP in GC. These miRNAs related to DDP resistance are summarized in Table IV.

A number of lncRNAs also modulate the chemosensitivity of GC cells to DDP. lncRNA HOTAIR inhibits the expression of miR-34a to promote DDP resistance in GC through the Wnt/ $\beta$-catenin and PI3K/Akt signaling pathways (109). Another study indicated that lncRNA HOTAIR functions as a ceRNA of miR-126 by inhibiting its expression and 
Table IV. ncRNAs related to cisplatin resistance in gastric cancer.

\begin{tabular}{|c|c|c|c|c|}
\hline ncRNA & Dysregulation & Effect on drug resistance & Pathway/target & Refs. \\
\hline $\operatorname{miR}-125 b$ & $\downarrow$ & Reversing & HER2 & $(84)$ \\
\hline $\operatorname{miR}-17-5 p$ & $\downarrow$ & Reversing & $\mathrm{p} 21$ & $(85)$ \\
\hline $\operatorname{miR}-22$ & $\downarrow$ & Reversing & ENO1 & $(86)$ \\
\hline miR-129 & $\downarrow$ & Reversing & P-gp & $(87)$ \\
\hline $\operatorname{miR}-148 a-3 p$ & $\downarrow$ & Reversing & Mitochondrial fission/AKAP1/RAB12/mTOR & $(88)$ \\
\hline miR-320a & $\downarrow$ & Reversing & ADAM10 & $(89)$ \\
\hline miR-181a & $\downarrow$ & Reversing & Autophagy/ATG5 & $(90)$ \\
\hline $\operatorname{miR}-203$ & $\downarrow$ & Reversing & Beiberine/bcl-w & $(91)$ \\
\hline $\operatorname{miR}-149$ & $\downarrow$ & Reversing & FoxM1 & $(92)$ \\
\hline $\operatorname{miR}-143$ & $\downarrow$ & Reversing & IGF1R/Bcl2 & (93) \\
\hline miR-26a & $\downarrow$ & Reversing & NRAS/E2F2 & (94) \\
\hline miR-1271 & $\downarrow$ & Reversing & IGF1R/IRS1/mTOR/Bcl-2 & $(95)$ \\
\hline miR-503 & $\downarrow$ & Reversing & IGF1R/Bcl-2 & (96) \\
\hline $\operatorname{miR}-25$ & $\uparrow$ & Inducing & FOXO3a & $(97)$ \\
\hline $\operatorname{miR}-214$ & $\uparrow$ & Inducing & EXO-anti-214 & (98) \\
\hline miR-99a & $\uparrow$ & Inducing & CAPNS1/calpain1/calpain2/caspase-3/PARP1 & $(83)$ \\
\hline $\operatorname{miR}-491$ & $\uparrow$ & Inducing & CAPNS1/calpain1/calpain2/caspase-3/PARP2 & $(83)$ \\
\hline $\operatorname{miR}-493$ & $\uparrow$ & Inducing & DKK1 & $(99)$ \\
\hline $\operatorname{miR}-421$ & $\uparrow$ & Inducing & E-cadherin/caspase-3 & $(100)$ \\
\hline $\operatorname{miR}-29 b$ & $\uparrow$ & Inducing & PI3K/Akt pathway & $(101)$ \\
\hline $\operatorname{miR}-141$ & $\uparrow$ & Inducing & KEAP1 & $(102)$ \\
\hline $\operatorname{miR}-132$ & $\downarrow$ & Inducing & SIRT1/CREB/ABCG2 & $(103)$ \\
\hline miR-524-5p & $\downarrow$ & Inducing & SOX9 & $(104)$ \\
\hline $\operatorname{miR}-34 a$ & $\downarrow$ & Inducing & MET & $(105)$ \\
\hline miR-200c & $\downarrow$ & Inducing & ZEB2/RhoE; E-cadherin & $(106-108)$ \\
\hline IncRNA HOTAIR & $\uparrow$ & Inducing & $\begin{array}{l}\mathrm{miR}-34 \mathrm{a} / \mathrm{PI} 3 \mathrm{~K} / \mathrm{Akt} \text { and } \mathrm{Wnt} / \beta \text {-catenin } \\
\text { pathway; miR-126/VEGFA/PIK3R2 and } \\
\text { PI3K/Akt/MRP1 pathway }\end{array}$ & $(109,110)$ \\
\hline lncRNA PVT1 & $\uparrow$ & Inducing & $\begin{array}{l}\text { mTOR/HIF-1 } \alpha / \mathrm{P}-\text { glycoprotein/MRP1 and } \\
\text { MDR1/MRP/mTOR/HIF-1 } \alpha \text { pathway }\end{array}$ & $(111,112)$ \\
\hline IncRNA GHET1 & $\uparrow$ & Inducing & $\mathrm{Bax} / \mathrm{Bcl} 2 / \mathrm{MDR} 1 / \mathrm{MRP} 1$ & $(113)$ \\
\hline lncRNA BCAR4 & $\uparrow$ & Inducing & Wnt signaling pathway & $(114)$ \\
\hline IncRNA AK022798 & $\uparrow$ & Inducing & Notch1/MRP1/P-gp/caspase-3/caspase- 8 & $(115)$ \\
\hline IncRNA CASC2 & $\downarrow$ & Reversing & miR-19a & $(116)$ \\
\hline
\end{tabular}

HER2, human epidermal growth factor receptor-2; ENO1, enolase1; P-gp, P-glycoprotein 1; AKAP1, a-kinase anchoring protein 1; RAB12, Ras-related protein Rab-12; mTOR, mammalian target of rapamycin; ADAM10, a disintegrin and metalloproteinase domain-containing protein 10; ATG5, autophagy related 5; FoxM1, forkhead box protein M1; IGF1R, insulin-like growth factor 1 receptor; Bcl-2, B-cell lymphoma-2; IRS1, insulin receptor substrate 1; FOXO3a, forkhead box O3a; CAPNS1, calpain small subunit 1; PARP, Poly ADP-ribose polymerase; DKK1, Dickkopf-1; PI3K, phosphoinositide 3-kinase; Akt, protein kinase B; KEAP1, Kelch-like ECH-associated protein 1; SIRT1, sirtuin 1; CREB, cAMP response element-binding protein; ABCG2, ATP-binding cassette super-family G member 2; ZEB2, zinc finger E-box binding homeobox 2; VEGFA, vascular endothelial growth factor A; PIK3R2, phosphatidylinositol 3-kinase regulatory subunit beta; MRP1, multidrug resistance-associated protein 1; MDR1, multidrug resistance protein 1; HIF-1 $\alpha$, hypoxia inducible factor-1; Bax, Bcl-2-associated X protein; Notch 1, Notch homolog 1; $\uparrow$, upregulation; $\downarrow$, downregulation.

increasing vascular endothelial growth factor A (VEGFA) and phosphatidylinositol 3-kinase regulatory subunit beta(PIK3R2) expression, thereby activating the PI3K/Akt/MRP1 signaling pathway (110). lncRNA PVT1 may promote resistance to DDP by increasing mTOR/HIF-1 $\alpha / \mathrm{P}-\mathrm{gp} / \mathrm{MRP} 1$ expression or increasing MDR1/MRP/mTOR/HIF-1 $\alpha$ expression $(111,112)$. lncRNA GHET1 enhances the resistance of GC cells to DDP by inhibiting Bax and increasing Bcl-2, MDR1 and MRP1 expression (113). IncRNA BCAR4 enhances resistance to DDP by upregulating certain unknown biomarkers through the Wnt signaling pathway (114). IncRNA AK022798 promotes the resistance of SGC7901/DDP and BGC823/DDP cells to DDP by upregulating MRP1 and P-gp and downregulating caspase-3 and caspase-8 (115). IncRNA CASC2 decreases the resistance 
Table V. ncRNAs related to 5-fluorouracil resistance in gastric cancer.

\begin{tabular}{|c|c|c|c|c|}
\hline ncRNA & Dysregulation & $\begin{array}{l}\text { Effect on drug } \\
\text { resistance }\end{array}$ & Pathway/target & Refs. \\
\hline miR-204 & $\downarrow$ & Reversing & EMT pathway/TGF- $\beta /$ TGF- $\beta$ R2 & $(117)$ \\
\hline $\operatorname{miR}-939$ & $\downarrow$ & Reversing & $\begin{array}{l}\text { SLC34A2 and Raf/mitogen-activated } \\
\text { protein kinase kinase/ERK pathway }\end{array}$ & $(118)$ \\
\hline miR-31 & $\downarrow$ & Reversing & RhoA & $(119)$ \\
\hline miR-BART15-3p & $\downarrow$ & Reversing & $T A X 1 B P 1 / \mathrm{NF}-\kappa \mathrm{B}$ & $(120)$ \\
\hline miR-197 & $\downarrow$ & Reversing & $M A P K 1$ & $(121)$ \\
\hline miR-193-3p & $\uparrow$ & Inducing & PTEN & $(122)$ \\
\hline lncRNA LEIGC & $\downarrow$ & Reversing & EMT pathway & $(123)$ \\
\hline
\end{tabular}

of GC to DDP by acting as a sponge for miR-19a (116). These lncRNAs related to DDP resistance in GC are summarized in Table IV.

Apart from DDP, other anti-cancer drugs are used in the treatment of GC in clinical therapy, including 5-FU, ADR, VCR, OXA, DOX, PTX and molecularly-targeted drugs. These anti-cancer drugs also play significant roles in the treatment of GC. However, similar to DDP-resistance, chemoresistance to these drugs frequently occurs in the clinical treatment of GC and can lead to therapeutic failure. Improving our understanding of the mechanisms leading to chemoresistance and reversing the process is therefore critical. Below we discuss the associations between dysregulated ncRNAs and the single anti-cancer drugs mentioned above in GC.

5-Fluorouracil. The overexpression of miR-204 has been shown to enhance sensitivity to $5-\mathrm{FU}$ in GC by inhibiting the EMT signaling pathway, and this effect is mediated by transforming growth factor- $\beta$ (TGF- $\beta$ ) and by targeting TGF- $\beta$ receptor 2 (TGF- $\beta$ R2) directly (117). miR-939 inhibits the Raf/mitogen-activated protein kinase kinase (MAP2K/MEK/MAPKK)/ERK signaling pathway to target solute carrier family 34 member 2 (SLC34A2), thereby decreasing the resistance of GC cells to 5-FU (118). The overexpression of miR-31 weakens resistance to 5-FU by decreasing the expression of RhoA in GC (119). miR-BART15-3p increases the chemosensitivity to $5-\mathrm{FU}$ by targeting the tax1-binding protein $1(T A X 1 B P 1)$ gene and modulating $\mathrm{NF}-\kappa \mathrm{B}$ activity in GC cells (120). The overexpression of miR-197 reverses resistance to 5-FU by targeting the MAPK1 gene (121).

However, miR-193-3p, which is upregulated in GC cells, enhances the 5-FU resistance of GC cells by targeting the PTEN gene directly (122). Few lncRNAs related to 5-FU resistance in GC cells have been identified in recent years. For example, lncRNA LEIGC has been shown to decrease the resistance of GC cells to 5-FU by modulating the EMT pathway (123).

All these ncRNAs and brief descriptions of their mechanisms of action as regards 5-FU resistance are presented in Table V.
Adriamycin/doxorubicin. The overexpression of miR-103/107 enhances the sensitivity of SGC7901/ADR cells to DOX by inhibiting P-gp function via the modulation of caveolin-1 (CAV-1) (124). miR-520h is upregulated by DOX in GC cells and inhibits histone deacetylase 1 (HDAC1) to reverse DOX resistance in GC cells (125).

In GC cells and patient tissue samples, the knockdown of miR-215p has been shown to increase PTEN and the tissue inhibitor of matrix metalloproteinases 3 (TIMP3) expression to weaken the drug resistance of GC to DOX (126). miR-140 is downregulated in GC cells and downregulates the expression of SOX4 and resistance-associated factors ATP-binding cassette sub-family $\mathrm{C}$ member 1 (ABCC1) and ATP-binding cassette super-family $\mathrm{G}$ member 2 (ABCG2) to promote the resistance of GC cells to DOX (127). miR-135a-5p reduces the sensitivity of BGC-823 cells to apoptosis to enhance ADR resistance by targeting activator protein (AP)-2 $\alpha$ and Bcl-2 (128). miR-19a/b induces ADR resistance by targeting PTEN directly (129). It also upregulates mdr1 and P-gp to promote the efflux of ADR, and regulates Bax and Bcl-2 to inhibit ADR-induced apoptosis (129).

IncRNA D63785 acts as a ceRNA of miR-422a, and prevents the suppression of myocyte enhancer factor 2D (MEF2D), which is dependent on miR-422a, inducing chemoresistance in GC (130). DOX promotes the apoptosis of GC cells, and the knockdown of miR-422a increases the sensitivity of GC cells to this process to reverse drug resistance (130). The expression level of 1ncRNA NEAT1 in SGC7901/ADR cells is upregulated, and it enhances ADR resistance by prevent apoptosis induced by ADR, although the potential target gene of NEAT1 remains unknown (131).

Vincristine. miR-647 is downregulated in GC, and the overexpression of miR-647 suppresses ankyrin-B (ANK2) activation and downregulates the expression of focal adhesion kinase (FAK), matrix metalloproteinase (MMP)-2 and MMP12 to reverse VCR resistance in GC (132). miR-1284 upregulates the expression of MYC and inhibits the expression of JUN and MMP12 by targeting eukaryotic initiation factor-4A (eIF4A1) 
Table VI. ncRNAs involved in taxane resistance in gastric cancer.

\begin{tabular}{lccccc}
\hline Drug & NcRNA & Dysregulation & Effect on drug resistance & Target/pathway & Refs. \\
\hline Paclitaxel & miR-34c-5p & $\downarrow$ & Reversing & MAPT & $(141)$ \\
Docetaxel & miR-361-5p & $\downarrow$ & Reversing & Autophagy/PI3K/Akt/mTOR & $(142)$ \\
Cabazitaxel & $/$ & $/$ & $/$ & $/$ & $/$ \\
Abraxane & $/$ & $/$ & $/$ & $/$ & $/$ \\
\hline
\end{tabular}

MAPT, microtubule-associated protein tau; PI3K, phosphoinositide 3-kinase; Akt, protein kinase B; mTOR, mammalian target of rapamycin; /, not mentioned; $\uparrow$, upregulation; $\downarrow$, downregulation.

to reduce the VCR resistance of GC cells (133). The ectopic expression of miR-497 has been shown to inhibit Bcl-2 to enhance the sensitivity of SGC7901/VCR cells to apoptosis induced by VCR (134). The overexpression of miR-181b inhibits Bcl-2 expression via the 3 '-UTR to decrease the resistance of SGC7901/VCR cells to VCR (135). The overexpression of miR-15b and miR-16 has been shown to prevent Bcl-2 expression to modulate VCR-induced apoptosis and decrease the resistance of SGC7901/VCR cells to VCR (136).

Zhu et al demonstrated that the miR-200bc/429 cluster, which is downregulated in MDR SGC7901/VCR cells, increased Bcl-2 and X-linked inhibitor of apoptosis protein (XIAP) expression to decrease the sensitivity of MDR SGC7901/VCR cells to apoptosis induced by VCR (137).

Oxaliplatin. The expression level of miR-135a in GC cells is upregulated and it inhibits the expression of E2F transcription factor 1 (E2F1) and the Sp1/Death-associated protein kinase 2 (DAPK2) signaling pathway to promote the resistance of GC cells to OXA (138).

IncRNA BLACTA1 is upregulated in GC cells and tissues exhibiting resistance to OXA (139). Furthermore, BLACTA1 targets miR-361 directly to induce the expression of the $\mathrm{ABCB} 1$ protein and promote the OXA resistance of GC (139).

Taxanes. Taxanes include classical drugs, such as PTX and DOC, as well as some novel ones, including cabazitaxel and abraxane (ABX) (140). PTX and DOC, known as classical potent cytotoxic drugs, have been used in the treatment of a number of types of cancer, including GC. Wu et al demonstrated that miR-34c-5p was downregulated in PTX-resistant GC cells and tissues (141). The overexpression of miR-34c-5p decreased microtubule-associated protein tau (MAPT) expression and enhanced the sensitivity of GC cells to PTX (141). Tian et al reported that the overexpression of miR-361-5p modulated the expression of FOXM1 by targeting the PI3K/Akt/mTOR pathway, thereby preventing chemoresistance to DOC induced by autophagy in GC (142). Cabazitaxel, a second-generation taxane that stabilizes microtubule, exhibits a broad spectrum anti-cancer activity (143). ABX, a new commercial albumin that binds paclitaxel nanoparticle, can be used in cytopharmaceuticals that induce tumor suppression in ovarian, breast, lung and pancreatic cancer, among others $(144,145)$. However, to date, there have been no reports of cabazitaxel resistance or ABX resistance in GC, at least to the best of our knowledge. The association between ncRNAs and resistance to taxanes in GC is summarized in Table VI.

Molecular targeted drugs. As one of the most rapidly developing fields, molecular targeted drugs play an important role in the treatment of GC. TZ and ramucirumab, which are first-line and second-line therapies for GC, and other specific targeted drugs, such as fibroblast growth factor receptor 2 (FGFR2) inhibitors and bromodomain and extra terminal (BET) inhibitors, are widely used in the clinical treatment of GC (146). Resistance to molecular targeted drugs has been reported previously. Venturutti et al reported that ectopically expressed miR-16 in TZ- and lapatinib-resistant GC cells targets cyclin J (CCNJ) and far upstream element-binding protein 1 (FUBP1) to reverse TZ and lapatinib resistance in ErbB-2-positive GC cells (147).

Another newly developing area, immune checkpoint molecules, has begun to attract increasing attention. Inhibiting the immune response of patients to cancer-specific antigens is a major mechanism of cancer development (148). The dysregulation of immune checkpoint molecules, including cytotoxic T-lymphocyte-associated antigen 4 (CTLA-4), programmed cell death protein-1 (PD-1) and its ligand PD-L1, can activate or suppress $\mathrm{T}$ lymphocytes, resulting in immune tolerance and cellular immune escape $(149,150)$. Therefore, immune checkpoint therapy, which is based on immune checkpoint inhibitors, can regulate immune response in tumor microenvironment and kill tumor cells indirectly (151). Several immune checkpoint inhibitors, including pembrolizumab, nivolumab, ipilimumab, atezolizumab, avelumab and durvalumab, which target CTLA-4, PD-1 and PD-L1, have been used in the clinical treatment of cancers such as GC, metastatic melanoma, non-small-cell lung cancer (NSCLC), head and neck squamous cell cancer, urothelial carcinoma and Hodgkin's lymphoma (152). Pembrolizumab was the first and only immune checkpoint inhibitor to be approved by the US Food and Drug Administration (FDA) as a third-line treatment for locally advanced and metastatic GC (153). However, to the best of our knowledge, there are no reports on pembrolizumab resistance in $\mathrm{GC}$ to date.

Immune checkpoint molecules and miRNAs are not separate. miRNAs have been reported to regulate the expression of immune checkpoint molecules to target its related pathways (154). For example, miR-138 has been shown to inhibit the expression of PD-1 and CTLA-4 on the surface of both regulatory T cells, thus promoting anti-cancer immunity in glioma cell lines (155). 


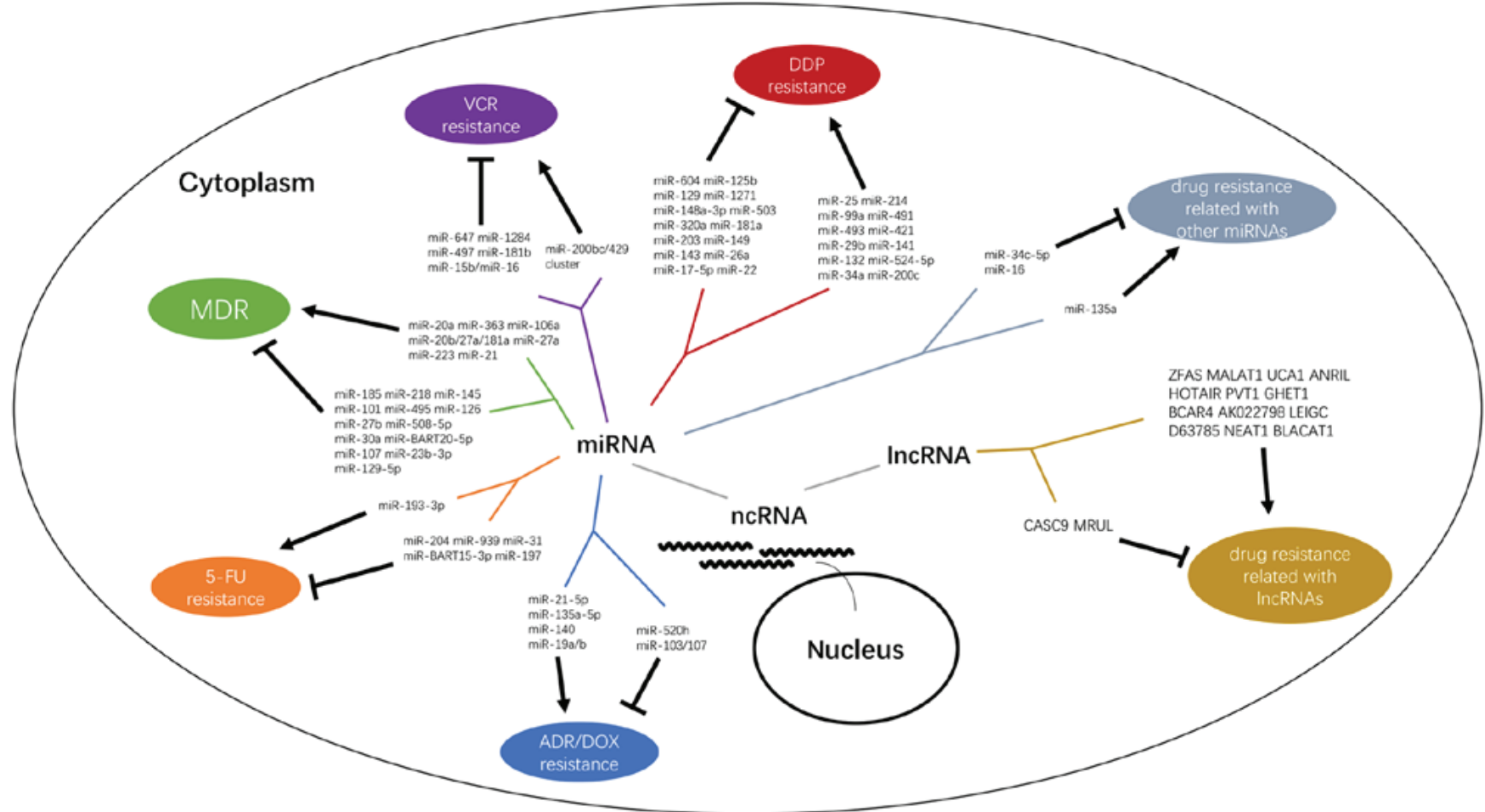

Figure 2. ncRNAs related to drug resistance in gastric cancer. Many ncRNAs are related to drug resistance in gastric cancer by modulating the sensitivity of gastric cancer cells to drugs, and the molecular mechanisms contribute to a complex regulatory network. Drug resistance related to other miRNAs (oxaliplatin resistance, paclitaxel resistance, trastuzumab resistance, lapatinib resistance, epirubicin resistance, oxaliplatin resistance, capecitabine resistance), drug resistance related to lncRNAs (cisplatin resistance, adriamycin resistance, oxaliplatin resistance, 5-fluorouracil resistance, paclitaxel resistance, vincristine resistance). The arrows represent an inducing effect and the T symbols indicate a reversing effect. ncRNAs, non-coding RNAs; ADR/DOX, adriamycin/doxorubicin; 5-FU, 5-fluorouracil; MDR, multi-drug resistance; VCR, vincristine; DDP, cisplatin.

A low expression of miR-197, which correlates with a high PD-L1 expression, promotes chemoresistance in NSCLC (156). Beyond miRNAs, some lncRNAs can also modulate immune checkpoint function $(157,158)$. However, the mechanisms how miRNAs and lncRNAs regulate the expression of immune checkpoint molecules in tumor microenvironment remain unclear.

In summary, the molecular mechanisms underlying the involvement of ncRNAs in single drug resistance in GC are varied and specific. However, certain common pathways and target genes involved in these mechanisms have been identified. A number of miRNAs can target the PTEN/PI3K/Akt, insulin-like growth factor 1 receptor (IGF1R)/insulin receptor substrate 1 (IRS1), MDR1/P-gp, Wnt/ $\beta$-catenin and mTOR pathways to modulate the chemoresistance of GC cells. Some of these ncRNAs can alter the sensitivity of GC cells to apoptosis induced by anti-cancer drugs via the Bcl-2/Bax/caspase family. Targeting E-cadherin to modulate EMT in GC cells is another frequently used approach. However, the majority of lncRNAs involved in single drug resistance are upregulated in GC cells. They modulate single drug resistance through several mechanisms, including the modulation of the PI3K/Akt pathway, the Wnt/ $\beta$-catenin pathway, the mTOR pathway and Bcl-2/Bax-induced apoptosis, and by acting as ceRNAs. The results described may provide novel potential biomarkers for the diagnosis and treatment of GC. These mechanisms contribute to the involvement of the large and complex network of ncRNAs in drug resistance.

\section{Conclusions and future directions}

Both miRNAs and lncRNAs play significant roles in modulating cancer chemosensitivity to regulate drug resistance in GC and form a complex regulating network (Fig. 2). The underlying molecular mechanisms include drug efflux, apoptosis dysfunction, DNA damage-induced repair, drug target modulation and proliferation triggering, among others (22). These miRNAs, IncRNAs, critical genes and proteins may be useful to predict the chemosensitivity of GC cells and to establish therapeutic strategies for different patients with GC.

Changes in ncRNA expression have been confirmed to contribute to the drug resistance of GC. Probably the selective regulation of ncRNA expression can partly enhance the sensitivity of GC cell lines to chemotherapy. At present, miRNA mimics and antagonists, which can imitate and silence the activity of specific miRNA, have been demonstrated to restore or antagonize miRNA functions $(159,160)$. Drugs based on these molecules have not been applied widely in clinical trials, apart from Miravirsen, the first miRNA-targeted drug for the treatment of hepatitis C virus (HCV) (161). Miravirsen can inhibit miR-122 to reduce the HCV RNA level by comprising a locked-nucleic acids (LNA) against miR-122 and now this drug has been examined in a phase II clinical trial(162). As previously described, lncRNAs can act as ceRNAs of some specific miRNAs to modulate their expression. This procession may provide a novel direction that modified or artificial lncRNAs can be designed and transmitted into cell lines to regulate expression of targeted miRNAs, although there is no report 
about drugs based on this mechanism to date, at least to the best of our knowledge. Another promising clinical application of ncRNAs is acting as potential biomarkers for diagnosis and chemosensitivity in GC. When circulating in the blood as free RNAs, miRNAs are quite stable and they can be easily detected in patients' biofluids (163). Some miRNAs, including miR-223, miR-16 and miR-100, have an increased expression in serum samples of patients with GC, which is associated with clinical characteristics, such as TNM stages $(21,164)$. Certain other miRNAs, such as miR-363, miR-519e and miR-520d have been reported to exhibit differential expression patterns in clinical samples derived from patients who can or cannot respond to chemotherapy $(25,165)$. A successful prediction of treatment response can be made, which would help design an effective and individual therapy planning rather than invalid chemotherapy, which has the risk of potential severe side-effects.

Although ncRNAs provide a novel direction for research on drug resistance in GC, they have not been extensively applied in clinical settings, such as in the diagnosis and treatment of GC. Chemical modification and delivery of ncRNA regulators into tumors are two well-known limitations to the clinical application of ncRNAs $(24,166)$. However, we believe that additional limitations exist. The safety of ncRNAs is an important problem that must be understood. RNA interference, another technique involving RNA, has been found to be toxic in preclinical mouse models $(167,168)$. Whether these specific markers could maintain their function continually during clinical application, in another word, the unexpected mutations, as well as polymorphisms of ncRNAs, may be another problem worth considering. Even slight mutation at some sites may alter the expression of miRNAs and lncRNAs, and influence their macro function. Real-time PCR and next-generation sequencing remain the most effective technologies for the accurate quantitative analysis of ncRNAs (22). Both technologies require precise instruments and skilled technical personnel and therefore are difficult and costly. If these limitations are overcome in the future, we believe that ncRNAs may be a novel field which can be used to reverse drug resistance and improve the prognosis of patients with GC.

In recent years, the ceRNA hypothesis has attracted increasing attention, although many of the functions of ceRNAs in tumors remain unknown, including their involvement in the drug resistance of cancer cells. Studies have indicated that IncRNAs can act as ceRNAs of miRNAs, and compete with the corresponding miRNAs for binding to targets to regulate drug resistance $(78,110,130)$. In addition, studies on the association between exosomes and drug resistance in cancer cells have been published recently. Exosomes play a role in drug resistance through different mechanisms, such as excreting anti-cancer drugs from tumor cells, interacting with oncogenic targets after competing with antibody-based anti-cancer drugs to reduce the curative effect, and contributing to transmit chemoresistance from drug-resistant cells to sensitive ones (169-172). For instance, Wang et al pointed out that drug resistance in GC was modulated by exosomes loaded with miRNA, mRNA and other ncRNAs via fusing with GC cells and modulating biological behaviors such as viability, migration, and apoptosis (98). In renal cell carcinoma cells, lncARSR transmitted by exosomes acts as a ceRNA to enhance sunitinib resistance by binding to miR34/miR-449 competitively (173). Another member of the ncRNA family, circular RNAs (circRNAs), has become the subject of research worldwide. circRNAs are related to carcinogenesis in breast cancer, bladder cancer, GC and colorectal cancer. circRNAs function by sponging miRNAs and regulating gene transcription and encoding proteins (174). For example, circPVT1 increases the expression of ABCB1 to enhance DOX and DDP resistance in osteosarcoma cells (175). Although drug resistance induced by circRNAs in GC has not been reported to date, at least to the best of our knowledge, it is reasonable to believe that drug resistance related to circRNAs and $\mathrm{GC}$ will be identified in the future.

These results provide new research areas and may help the design of potential therapeutic strategies with which to reverse drug resistance in different patients in the future. The mechanisms of drug resistance are complex, and more extensive and comprehensive studies are required in order to elucidate the mechanisms of anti-cancer drug resistance in GC in the future.

\section{Acknowledgements}

Not applicable.

\section{Funding}

This study was supported by the grant of Jilin Provincial Health and Family Planning Commission Training Plan of Young and Technological Core Project (2016Q023), Jilin Provincial Science and Technology Development Planning Project (20180101169JC), Jilin Provincial Health and Family Planning Commission Project (2016C051-2).

\section{Availability of data and materials}

Not applicable.

\section{Authors' contributions}

All authors (CC, XT, YL, JZ and JL) were involved in the conception and design of the study, and have taken the responsibility for publishing this review article. CC searched literature, wrote the manuscript, and designed the pictures; $\mathrm{XT}$ and YL were involved in designing the tables; CC, JZ and $\mathrm{JL}$ were involved in the revision of the manuscript. JZ was responsible for technical or material support. All authors have read and approved the final manuscript.

\section{Ethics approval and consent to participate}

Not applicable.

\section{Patient consent for publication}

Not applicable.

\section{Competing interests}

The authors declare that they have no competing interests. 


\section{References}

1. Siegel RL, Miller KD and Jemal A: Cancer Statistics, 2017. CA Cancer J Clin 67: 7-30, 2017.

2. Chen W, Zheng R, Baade PD, Zhang S, Zeng H, Bray F, Jemal A Yu XQ and He J: Cancer statistics in China, 2015. CA Cancer J Clin 66: 115-132, 2016.

3. Cunningham D, Allum WH, Stenning SP, Thompson JN, Van de Velde CJ, Nicolson M, Scarffe JH, Lofts FJ, Falk SJ, Iveson TJ, et al; MAGIC Trial Participants: Perioperative chemotherapy versus surgery alone for resectable gastroesophagea cancer. N Engl J Med 355: 11-20, 2006.

4. Marin JJ,Al-Abdulla R, Lozano E, Briz O, Bujanda L, Banales JM and Macias RI: Mechanisms of resistance to chemotherapy in gastric cancer. Anticancer Agents Med Chem 16: 318-334, 2016.

5. Ruffell B and Coussens LM: Macrophages and therapeutic resistance in cancer. Cancer Cell 27: 462-472, 2015.

6. Garrido M, Fonseca PJ, Vieitez JM, Frunza M and Lacave AJ Challenges in first line chemotherapy and targeted therapy in advanced gastric cancer. Expert Rev Anticancer Ther 14: 887-900, 2014.

7. Zheng T, Wang J, Chen X and Liu L: Role of microRNA in anticancer drug resistance. Int J Cancer 126: 2-10, 2010.

8. Dembinski JL and Krauss S: Characterization and functional analysis of a slow cycling stem cell-like subpopulation in pancreas adenocarcinoma. Clin Exp Metastasis 26: 611-623, 2009.

9. Saxena M, Stephens MA,Pathak H and Rangarajan A: Transcription factors that mediate epithelial-mesenchymal transition lead to multidrug resistance by upregulating $\mathrm{ABC}$ transporters. Cell Death Dis 2: e179, 2011.

10. Vega S, Morales AV, Ocaña OH, Valdés F, Fabregat I and Nieto MA: Snail blocks the cell cycle and confers resistance to cell death. Genes Dev 18: 1131-1143, 2004.

11. Terry S, Savagner P, Ortiz-Cuaran S, Mahjoubi L, Saintigny P, Thiery JP and Chouaib S: New insights into the role of EMT in tumor immune escape. Mol Oncol 11: 824-846, 2017.

12. Toledo-Guzmán ME, Bigoni-Ordóñez GD, Ibáñez Hernández M and Ortiz-Sánchez E: Cancer stem cell impact on clinical oncology. World J Stem Cells 10: 183-195, 2018.

13. Reya T, Morrison SJ, Clarke MF and Weissman IL: Stem cells, cancer, and cancer stem cells. Nature 414: 105-111, 2001.

14. Al-Hajj M, Wicha MS, Benito-Hernandez A, Morrison SJ and Clarke MF: Prospective identification of tumorigenic breast cancer cells. Proc Natl Acad Sci USA 100: 3983-3988, 2003

15. Catalano V, Di Franco S, Iovino F, Dieli F, Stassi G and Todaro M: CD133 as a target for colon cancer. Expert Opin Ther Targets 16: 259-267, 2012

16. Abdullah LN and Chow EK: Mechanisms of chemoresistance in cancer stem cells. Clin Transl Med 2: 3, 2013.

17. Eyre R, Harvey I, Stemke-Hale K, Lennard TW, Tyson-Capper A and Meeson AP: Reversing paclitaxel resistance in ovarian cancer cells via inhibition of the ABCB1 expressing side population. Tumour Biol 35: 9879-9892, 2014.

18. Tanei T, Morimoto K, Shimazu K, Kim SJ, Tanji Y, Taguchi T, Tamaki Y and Noguchi S: Association of breast cancer stem cells identified by aldehyde dehydrogenase 1 expression with resistance to sequential Paclitaxel and epirubicin-based chemotherapy for breast cancers. Clin Cancer Res 15: 4234-4241, 2009.

19. Zhao J: Cancer stem cells and chemoresistance: The smartest survives the raid. Pharmacol Ther 160: 145-158, 2016.

20. Sahu A, Singhal U and Chinnaiyan AM: Long noncoding RNAs in cancer: From function to translation. Trends Cancer 1: 93-109, 2015.

21. Yang Q, Zhang RW, Sui PC, He HT and Ding L: Dysregulation of non-coding RNAs in gastric cancer. World J Gastroenterol 21: 10956-10981, 2015.

22. Ayers D and Vandesompele J: Influence of microRNAs and long non-coding RNAs in cancer chemoresistance. Genes (Basel) 8 8, 2017.

23. Farazi TA, Hoell JI, Morozov P and Tuschl T: MicroRNAs in human cancer. Adv Exp Med Biol 774: 1-20, 2013.

24. Riquelme I, Letelier P, Riffo-Campos AL, Brebi P and Roa JC: Emerging role of miRNAs in the drug resistance of gastric cancer. Int J Mol Sci 17: 424, 2016.

25. Matuszcak C, Haier J, Hummel R and Lindner K: MicroRNAs: Promising chemoresistance biomarkers in gastric cancer with diagnostic and therapeutic potential. World J Gastroenterol 20: 13658-13666, 2014.
26. Geisler S and Coller J: RNA in unexpected places: Long noncoding RNA functions in diverse cellular contexts. Nat Rev Mol Cell Biol 14: 699-712, 2013.

27. Delás MJ and Hannon GJ: lncRNAs in development and disease: From functions to mechanisms. Open Biol 7: 7, 2017.

28. Heery R, Finn SP, Cuffe S and Gray SG: Long non-coding RNAs Key regulators of epithelial-mesenchymal transition, tumour drug resistance and cancer stem cells. Cancers (Basel) 9: 9, 2017

29. Yuan L, Xu B, Yuan P, Zhou J, Qin P, Han L, Chen G, Wang Z, Run Z, Zhao P, et al: Tumor-infiltrating CD4 ${ }^{+} \mathrm{T}$ cells in patients with gastric cancer. Cancer Cell Int 17: 114, 2017.

30. Wang LL, Zhang XH, Zhang X and Chu JK: MiR-30a increases cisplatin sensitivity of gastric cancer cells through suppressing epithelial-to-mesenchymal transition (EMT). Eur Rev Med Pharmacol Sci 20: 1733-1739, 2016.

31. Archie V, Kauh J, Jones DV Jr, Cruz V, Karpeh MS Jr and Thomas CR Jr: Gastric cancer: Standards for the 21st century. Crit Rev Oncol Hematol 57: 123-131, 2006.

32. Szakács G, Paterson JK, Ludwig JA, Booth-Genthe C and Gottesman MM: Targeting multidrug resistance in cancer. Nat Rev Drug Discov 5: 219-234, 2006.

33. Zhang XL, Shi HJ, Wang JP, Tang HS and Cui SZ: MiR-218 inhibits multidrug resistance (MDR) of gastric cancer cells by targeting Hedgehog/smoothened. Int J Clin Exp Pathol 8: 6397-6406, 2015

34. An Y, Zhang Z, Shang Y, Jiang X, Dong J, Yu P, Nie Y and Zhao Q: miR-23b-3p regulates the chemoresistance of gastric cancer cells by targeting ATG12 and HMGB2. Cell Death Dis 6 : e1766, 2015.

35. Zhang Y, Lu Q and Cai X: MicroRNA-106a induces multidrug resistance in gastric cancer by targeting RUNX3. FEBS Lett 587: 3069-3075, 2013

36. Kondo T, Wakayama T, Naiki T, Matsumoto K and Sugimoto K: Recruitment of Mec1 and Ddc1 checkpoint proteins to doublestrand breaks through distinct mechanisms. Science 294 867-870, 2001

37. Özeş AR, Miller DF, Özeş ON, Fang F, Liu Y, Matei D, Huang T and Nephew KP: NF- $\mathrm{BB}-\mathrm{HOTAIR}$ axis links DNA damage response, chemoresistance and cellular senescence in ovarian cancer. Oncogene 35: 5350-5361, 2016.

38. Lin CT, Lyu YL, Xiao H,Lin WH and Whang-Peng J: Suppression of gene amplification and chromosomal DNA integration by the DNA mismatch repair system. Nucleic Acids Res 29: 3304-3310, 2001.

39. Ferguson DO and Alt FW: DNA double strand break repair and chromosomal translocation: Lessons from animal models. Oncogene 20: 5572-5579, 2001.

40. Zugazagoitia J, Guedes C, Ponce S, Ferrer I, Molina-Pinelo S and Paz-Ares L: Current challenges in cancer treatment. Clin Ther 38: 1551-1566, 2016.

41. Schlösser HA, Drebber U, Kloth M, Thelen M, Rothschild SI, Haase S, Garcia-Marquez M, Wennhold K, Berlth F, Urbanski A, et al: Immune checkpoints programmed death 1 ligand 1 and cytotoxic T lymphocyte associated molecule 4 in gastric adenocarcinoma. OncoImmunology 5: e1100789, 2015.

42. Jabbour E, Kantarjian H and Cortes J: Use of second- and thirdgeneration tyrosine kinase inhibitors in the treatment of chronic myeloid leukemia: An evolving treatment paradigm. Clin Lymphoma Myeloma Leuk 15: 323-334, 2015.

43. Szakács G, Jakab K, Antal F and Sarkadi B: Diagnostics of multidrug resistance in cancer. Pathol Oncol Res 4: 251-257, 1998.

44. Tan B, Li Y, Zhao Q, Fan L and Wang D: ZNF139 increases multidrug resistance in gastric cancer cells by inhibiting miR-185. Biosci Rep 38: 38, 2018

45. Li Q, Wang JX, He YQ, Feng C, Zhang XJ, Sheng JQ and Li PF: MicroRNA-185 regulates chemotherapeutic sensitivity in gastric cancer by targeting apoptosis repressor with caspase recruitment domain. Cell Death Dis 5: e1197, 2014

46. Zhang XL, Shi HJ, Wang JP, Tang HS, Wu YB, Fang ZY, Cui SZ and Wang LT: MicroRNA-218 is upregulated in gastric cancer after cytoreductive surgery and hyperthermic intraperitoneal chemotherapy and increases chemosensitivity to cisplatin. World J Gastroenterol 20: 11347-11355, 2014.

47. Zeng JF, Ma XQ, Wang LP and Wang W: MicroRNA-145 exerts tumor-suppressive and chemo-resistance lowering effects by targeting CD44 in gastric cancer. World J Gastroenterol 23: 2337-2345, 2017.

48. Li G, Yang F, Gu S, Li Z and Xue M: MicroRNA-101 induces apoptosis in cisplatin-resistant gastric cancer cells by targeting VEGF-C. Mol Med Rep 13: 572-578, 2016. 
49. Bao J, Xu Y, Wang Q, Zhang J, Li Z, Li D and Li J: miR-101 alleviates chemoresistance of gastric cancer cells by targeting ANXA2. Biomed Pharmacother 92: 1030-1037, 2017.

50. Zou Z, Zou R, Zong D, Shi Y, Chen J, Huang J, Zhu J, Chen L, Bao X, Liu Y, et al: miR-495 sensitizes MDR cancer cells to the combination of doxorubicin and taxol by inhibiting MDR1 expression. J Cell Mol Med 21: 1929-1943, 2017.

51. Wang P, Li Z, Liu H, Zhou D, Fu A and Zhang E: MicroRNA-126 increases chemosensitivity in drug-resistant gastric cancer cells by targeting EZH2. Biochem Biophys Res Commun 479: 91-96, 2016.

52. Shang Y, Zhang Z, Liu Z, Feng B, Ren G, Li K, Zhou L, Sun Y, Li M, Zhou J, et al: miR-508-5p regulates multidrug resistance of gastric cancer by targeting ABCB1 and ZNRD1. Oncogene 33: 3267-3276, 2014

53. Shang Y, Feng B, Zhou L, Ren G, Zhang Z, Fan X, Sun Y, Luo G, Liang J, Wu K, et al: The miR27b-CCNG1-P53-miR-508-5p axis regulates multidrug resistance of gastric cancer. Oncotarget 7 : $538-549,2016$

54. Du X, Liu B, Luan X, Cui Q and Li L: miR-30 decreases multidrug resistance in human gastric cancer cells by modulating cell autophagy. Exp Ther Med 15: 599-605, 2018.

55. Li C, Zou J, Zheng G and Chu J: miR-30a decreases multidrug resistance (MDR) of gastric cancer cells. Med Sci Monit 22: 4509-4515, 2016.

56. Teng R, Hu Y, Zhou J, Seifer B, Chen Y, Shen J and Wang L: Overexpression of Lin 28 decreases the chemosensitivity of gastric cancer cells to oxaliplatin, paclitaxel, doxorubicin, and fluorouracil in part via microRNA-107. PLoS One 10: e0143716, 2015.

57. Kim H, Choi H and Lee SK: Epstein-Barr virus miR-BART20-5p regulates cell proliferation and apoptosis by targeting BAD. Cancer Lett 356: 733-742, 2015.

58. Wu Q, Yang Z, Xia L, Nie Y, Wu K, Shi Y and Fan D: Methylation of miR-129-5p CpG island modulates multi-drug resistance in gastric cancer by targeting $\mathrm{ABC}$ transporters. Oncotarget 5: $11552-11563,2014$.

59. Zhou L, Li X, Zhou F, Jin Z, Chen D, Wang P, Zhang S, Zhuge Y, Shang Y and Zou X: Downregulation of leucine-rich repeats and immunoglobulin-like domains 1 by microRNA-20a modulates gastric cancer multidrug resistance. Cancer Sci 109: 1044-1054, 2018.

60. Du Y, Zhu M, Zhou X, Huang Z, Zhu J, Xu J, Cheng G, Shu Y, Liu P, Zhu W, et al: miR-20a enhances cisplatin resistance of human gastric cancer cell line by targeting NFKBIB. Tumour Biol 37: 1261-1269, 2016

61. Zhu M, Zhou X, Du Y, Huang Z, Zhu J, Xu J, Cheng G, Shu Y, Liu $\mathrm{P}, \mathrm{Zhu} \mathrm{W}$, et al: miR-20a induces cisplatin resistance of a human gastric cancer cell line via targeting CYLD. Mol Med Rep 14: 1742-1750, 2016.

62. Li X, Zhang Z, Yu M, Li L, Du G, Xiao W and Yang H: Involvement of miR-20a in promoting gastric cancer progression by targeting early growth response 2 (EGR2). Int J Mol Sci 14 16226-16239, 2013.

63. Zhang PF, Sheng LL, Wang G, Tian M, Zhu LY, Zhang R, Zhang $\mathrm{J}$ and Zhu JS: miR-363 promotes proliferation and chemo-resistance of human gastric cancer via targeting of FBW7 ubiquitin ligase expression. Oncotarget 7: 35284-35292, 2016.

64. Fang Y, Shen H, Li H, Cao Y, Qin R, Long L, Zhu X, Xie C and $\mathrm{Xu}$ W: miR-106a confers cisplatin resistance by regulating PTEN/Akt pathway in gastric cancer cells. Acta Biochim Biophys Sin (Shanghai) 45: 963-972, 2013.

65. Danza K, Silvestris N, Simone G, Signorile M, Saragoni L, Brunetti O, Monti M, Mazzotta A, De Summa S, Mangia A, et al: Role of miR-27a, miR-181a and miR-20b in gastric cancer hypoxia-induced chemoresistance. Cancer Biol Ther 17: 400-406, 2016

66. Zhao Q, Li Y, Tan BB, Fan LQ, Yang PG and Tian Y: HIF-1 $\alpha$ induces multidrug resistance in gastric cancer cells by inducing miR-27a. PLoS One 10: e0132746, 2015.

67. Zhao X, Yang L and Hu J: Down-regulation of miR-27a might inhibit proliferation and drug resistance of gastric cancer cells. J Exp Clin Cancer Res 30: 55, 2011.

68. Huang D, Wang H, Liu R, Li H, Ge S, Bai M, Deng T, Yao G and $\mathrm{Ba} Y$ : miRNA27a is a biomarker for predicting chemosensitivity and prognosis in metastatic or recurrent gastric cancer. J Cell Biochem 115: 549-556, 2014.

69. Zhou X, Jin W, Jia H, Yan J and Zhang G: MiR-223 promotes the cisplatin resistance of human gastric cancer cells via regulating cell cycle by targeting FBXW7. J Exp Clin Cancer Res 34: 28, 2015 .
70. Eto K, Iwatsuki M, Watanabe M, Ishimoto T, Ida S, Imamura Y, Iwagami S, Baba Y, Sakamoto Y, Miyamoto Y, et al: The sensitivity of gastric cancer to trastuzumab is regulated by the miR-223/FBXW7 pathway. Int J Cancer 136: 1537-1545, 2015.

71. Yang SM, Huang C, Li XF, Yu MZ, He Y and Li J: miR-21 confers cisplatin resistance in gastric cancer cells by regulating PTEN. Toxicology 306: 162-168, 2013.

72. Jin B, Liu Y and Wang H: Antagonism of miRNA-21 sensitizes human gastric cancer cells to paclitaxel. Cell Biochem Biophys 72: 275-282, 2015.

73. Eto K, Iwatsuki M, Watanabe M, Ida S, Ishimoto T, Iwagami S, Baba Y, Sakamoto Y, Miyamoto Y, Yoshida N, et al: The microRNA-21/PTEN pathway regulates the sensitivity of HER2positive gastric cancer cells to trastuzumab. Ann Surg Oncol 21: 343-350, 2014

74. Chen QN, Wei CC, Wang ZX and Sun M: Long non-coding RNAs in anti-cancer drug resistance. Oncotarget 8: 1925-1936, 2017.

75. Shang C, Sun L, Zhang J, Zhao B, Chen X, Xu H and Huang B: Silence of cancer susceptibility candidate 9 inhibits gastric cancer and reverses chemoresistance. Oncotarget 8: 15393-15398, 2017.

76. Wang Y, Zhang D, Wu K, Zhao Q, Nie Y and Fan D: Long noncoding RNA MRUL promotes ABCB1 expression in multidrug-resistant gastric cancer cell sublines. Mol Cell Biol 34: 3182-3193, 2014

77. Xu W, He L, Li Y, Tan Y, Zhang F and Xu H: Silencing of lncRNA ZFAS1 inhibits malignancies by blocking Wnt/ $\beta$-catenin signaling in gastric cancer cells. Biosci Biotechnol Biochem 82: 456-465, 2018

78. YiRen H, Ying Cong Y, Sunwu Y, Keqin L, Xiaochun T, Senrui C, Ende C, XiZhou L and Yanfan C: Long noncoding RNA MALAT1 regulates autophagy associated chemoresistance via miR-23b-3p sequestration in gastric cancer. Mol Cancer 16: 174, 2017.

79. Fang Q, Chen X and Zhi X: Long Non-Coding RNA (LncRNA) Urothelial Carcinoma Associated 1 (UCA1) Increases Multi-Drug Resistance of Gastric Cancer via Downregulating miR-27b. Med Sci Monit 22: 3506-3513, 2016.

80. Shang C, Guo Y, Zhang J and Huang B: Silence of long noncoding RNA UCA1 inhibits malignant proliferation and chemotherapy resistance to adriamycin in gastric cancer. Cancer Chemother Pharmacol 77: 1061-1067, 2016.

81. Lan WG, Xu DH, Xu C, Ding CL, Ning FL, Zhou YL, Ma LB, Liu CM and Han X: Silencing of long non-coding RNA ANRIL inhibits the development of multidrug resistance in gastric cancer cells. Oncol Rep 36: 263-270, 2016.

82. Florea AM and Büsselberg D: Cisplatin as an anti-tumor drug: Cellular mechanisms of activity, drug resistance and induced side effects. Cancers (Basel) 3: 1351-1371, 2011.

83. Zhang Y, Xu W, Ni P, Li A, Zhou J and Xu S: MiR-99a and MiR-491 regulate cisplatin resistance in human gastric cancer cells by targeting CAPNS1. Int J Biol Sci 12: 1437-1447, 2016.

84. Zhang X, Yao J, Guo K, Huang H, Huai S, Ye R, Niu B, Ji T, $\mathrm{Han} \mathrm{W}$ and $\mathrm{Li}$ J: The functional mechanism of miR-125b in gastric cancer and its effect on the chemosensitivity of cisplatin. Oncotarget 9: 2105-2119, 2017

85. Wang Z and Ji F: Downregulation of microRNA-17-5p inhibits drug resistance of gastric cancer cells partially through targeting p21. Oncol Lett 15: 4585-4591, 2018

86. Qian X, Xu W, Xu J, Shi Q, Li J, Weng Y, Jiang Z, Feng L, Wang X, Zhou J, et al: Enolase 1 stimulates glycolysis to promote chemoresistance in gastric cancer. Oncotarget 8: 47691-47708, 2017.

87. Lu C, Shan Z, Li C and Yang L: MiR-129 regulates cisplatinresistance in human gastric cancer cells by targeting P-gp. Biomed Pharmacother 86: 450-456, 2017.

88. Li B, Wang W, Li Z, Chen Z, Zhi X, Xu J, Li Q, Wang L, Huang X, Wang L, et al: MicroRNA-148a-3p enhances cisplatin cytotoxicity in gastric cancer through mitochondrial fission induction and cyto-protective autophagy suppression. Cancer Lett 410: 212-227, 2017

89. Ge X, Cui H, Zhou Y, Yin D, Feng Y, Xin Q, Xu X, Liu W, Liu S and Zhang Q: miR-320a modulates cell growth and chemosensitivity via regulating ADAM10 in gastric cancer. Mol Med Rep 16: 9664-9670, 2017

90. Zhao J, Nie Y, Wang H and Lin Y: MiR-181a suppresses autophagy and sensitizes gastric cancer cells to cisplatin. Gene 576: 828-833, 2016

91. You HY, Xie XM, Zhang WJ, Zhu HL and Jiang FZ: Berberine modulates cisplatin sensitivity of human gastric cancer cells by upregulation of miR-203. In Vitro Cell Dev Biol Anim 52: 857-863, 2016. 
92.Li X, Liang J, Liu YX, Wang Y, Yang XH, Luan BH, Zhang GL, Du J and Wu XH: miR-149 reverses cisplatin resistance of gastric cancer SGC7901/DDP cells by targeting FoxM1. Pharmazie 71: 640-643, 2016.

93.Zhuang M, Shi Q, Zhang X, Ding Y, Shan L, Shan X, Qian J, Zhou X, Huang Z, Zhu W, et al: Involvement of miR-143 in cisplatin resistance of gastric cancer cells via targeting IGF1R and BCL2. Tumour Biol 36: 2737-2745, 2015.

94. Wen L, Cheng F, Zhou Y and Yin C: MiR-26a enhances the sensitivity of gastric cancer cells to cisplatin by targeting NRAS and E2F2. Saudi J Gastroenterol 21: 313-319, 2015.

95. Yang M, Shan X, Zhou X, Qiu T, Zhu W, Ding Y, Shu Y and Liu P: miR-1271 regulates cisplatin resistance of human gastric cancer cell lines by targeting IGF1R, IRS1, mTOR, and BCL2. Anticancer Agents Med Chem 14: 884-891, 2014.

96. Wang T, Ge G, Ding Y, Zhou X, Huang Z, Zhu W, Shu Y and Liu P: MiR-503 regulates cisplatin resistance of human gastric cancer cell lines by targeting IGF1R and BCL2. Chin Med J (Engl) 127: 2357-2362, 2014.

97. He J, Qi H, Chen F and Cao C: MicroRNA-25 contributes to cisplatin resistance in gastric cancer cells by inhibiting forkhead box O3a. Oncol Lett 14: 6097-6102, 2017.

98. Wang X, Zhang H, Bai M, Ning T, Ge S, Deng T, Liu R, Zhang L, Ying $\mathrm{G}$ and $\mathrm{Ba}$ Y: Exosomes serve as nanoparticles to deliver anti-miR-214 to reverse chemoresistance to cisplatin in gastric cancer. Mol Ther 26: 774-783, 2018.

99. Jia X, Li N, Peng C, Deng Y, Wang J, Deng M, Lu M, Yin J, Zheng G, Liu H, et al: miR-493 mediated DKK1 down-regulation confers proliferation, invasion and chemo-resistance in gastric cancer cells. Oncotarget 7: 7044-7054, 2016.

100. Ge X, Liu X, Lin F, Li P, Liu K, Geng R, Dai C, Lin Y, Tang W, Wu Z, et al: MicroRNA-421 regulated by HIF-1 $\alpha$ promotes metastasis, inhibits apoptosis, and induces cisplatin resistance by targeting E-cadherin and caspase-3 in gastric cancer. Oncotarget 7: 24466-24482, 2016.

101. Chen DD, Feng LC, Ye R, He YQ and Wang YD: miR-29b reduces cisplatin resistance of gastric cancer cell by targeting PI3K/Akt pathway. Zhongguo Yi Xue Ke Xue Yuan Xue Bao 37: 514-519, 2015 (In Chinese).

102.Zhou X, Su J, Zhu L and Zhang G: Helicobacter pylori modulates cisplatin sensitivity in gastric cancer by down-regulating miR-141 expression. Helicobacter 19: 174-181, 2014.

103. Zhang L, Guo X, Zhang D, Fan Y, Qin L, Dong S and Zhang L: Upregulated miR-132 in $\mathrm{Lgr}^{+}$gastric cancer stem cell-like cells contributes to cisplatin-resistance via SIRT1/CREB/ABCG2 signaling pathway. Mol Carcinog 56: 2022-2034, 2017.

104.Wang J, Xue X, Hong H, Qin M, Zhou J, Sun Q, Liang H and Gao L: Upregulation of microRNA-524-5p enhances the cisplatin sensitivity of gastric cancer cells by modulating proliferation and metastasis via targeting SOX9. Oncotarget 8: 574-582, 2017.

105.Zhang Z, Kong Y, Yang W, Ma F, Zhang Y, Ji S, Ma EM, Liu H, Chen Y and Hua Y: Upregulation of microRNA-34a enhances the DDP sensitivity of gastric cancer cells by modulating proliferation and apoptosis via targeting MET. Oncol Rep 36: 2391-2397, 2016

106. Jiang T, Dong P, Li L, Ma X, Xu P, Zhu H, Wang Y, Yang B, Liu K, Liu J, et al: MicroRNA-200c regulates cisplatin resistance by targeting ZEB2 in human gastric cancer cells. Oncol Rep 38 $151-158,2017$

107. Chang L, Guo F, Wang Y, Lv Y, Huo B, Wang L and Liu W: MicroRNA-200c regulates the sensitivity of chemotherapy of gastric cancer SGC7901/DDP cells by directly targeting RhoE. Pathol Oncol Res 20: 93-98, 2014.

108. Chen Y, Zuo J, Liu Y, Gao H and Liu W: Inhibitory effects of miRNA-200c on chemotherapy-resistance and cell proliferation of gastric cancer SGC7901/DDP cells. Chin J Cancer 29: 1006-1011, 2010.

109. Cheng C, Qin Y, Zhi Q, Wang J and Qin C: Knockdown of long non-coding RNA HOTAIR inhibits cisplatin resistance of gastric cancer cells through inhibiting the PI3K/Akt and Wnt/ $\beta$ catenin signaling pathways by up-regulating miR-34a. Int J Biol Macromol 107: 2620-2629, 2018.

110. Yan J, Dang Y, Liu S, Zhang Y and Zhang G: LncRNA HOTAIR promotes cisplatin resistance in gastric cancer by targeting miR-126 to activate the PI3K/AKT/MRP1 genes. Tumour Biol 37: 16345-16355, 2016.

111. Zhou DD, Liu XF, Lu CW, Pant OP and Liu XD: Long noncoding RNA PVT1: Emerging biomarker in digestive system cancer. Cell Prolif 50: 50, 2017.
112. Zhang XW, Bu P, Liu L, Zhang XZ and Li J: Overexpression of long non-coding RNA PVT1 in gastric cancer cells promotes the development of multidrug resistance. Biochem Biophys Res Commun 462: 227-232, 2015.

113. Zhang X, Bo P, Liu L, Zhang X and Li J: Overexpression of long non-coding RNA GHET1 promotes the development of multidrug resistance in gastric cancer cells. Biomed Pharmacother 92: 580-585, 2017.

114. Wang L, Chunyan Q, Zhou Y, He Q, Ma Y, Ga Y and Wang X: BCAR4 increase cisplatin resistance and predicted poor survival in gastric cancer patients. Eur Rev Med Pharmacol Sci 21: 4064-4070, 2017.

115. Hang Q, Sun R,Jiang C and Li Y: Notch 1 promotes cisplatin-resistant gastric cancer formation by upregulating lncRNA AK022798 expression. Anticancer Drugs 26: 632-640, 2015

116. Li Y, Lv S, Ning H, Li K, Zhou X, Xv H and Wen H: Downregulation of CASC2 contributes to cisplatin resistance in gastric cancer by sponging miR-19a. Biomed Pharmacother 108: $1775-1782,2018$

117. Li LQ, Pan D, Chen Q, Zhang SW, Xie DY, Zheng XL and Chen $\mathrm{H}$ : Sensitization of gastric cancer cells to 5-FU by microRNA-204 through targeting the TGFBR2-mediated epithelial to mesenchymal transition. Cell Physiol Biochem 47: $1533-1545,2018$

118. Zhang JX, Xu Y, Gao Y, Chen C, Zheng ZS, Yun M, Weng HW, Xie D and Ye S: Decreased expression of miR-939 contributes to chemoresistance and metastasis of gastric cancer via dysregulation of SLC34A2 and Raf/MEK/ERK pathway. Mol Cancer 16: 18, 2017

119. Korourian A, Roudi R, Shariftabrizi A and Madjd Z: MicroRNA-31 inhibits RhoA-mediated tumor invasion and chemotherapy resistance in MKN-45 gastric adenocarcinoma cells. Exp Biol Med (Maywood) 242: 1842-1847, 2017

120. Choi $\mathrm{H}$ and Lee SK: TAX1BP1 downregulation by EBV-miR-BART15-3p enhances chemosensitivity of gastric cancer cells to 5-FU. Arch Virol 162: 369-377, 2017.

121. Xiong HL, Zhou SW, Sun AH, He Y, Li J and Yuan X: MicroRNA 197 reverses the drug resistance of fluorouracil induced SGC7901 cells by targeting mitogen activated protein kinase 1. Mol Med Rep 12: 5019-5025, 2015.

122. Jian B, Li Z, Xiao D, He G, Bai L and Yang Q: Downregulation of microRNA-193-3p inhibits tumor proliferation migration and chemoresistance in human gastric cancer by regulating PTEN gene. Tumour Biol 37: 8941-8949, 2016.

123. Han Y, Ye J, Wu D, Wu P, Chen Z, Chen J, Gao S and Huang J: LEIGC long non-coding RNA acts as a tumor suppressor in gastric carcinoma by inhibiting the epithelial-to-mesenchymal transition. BMC Cancer 14: 932, 2014.

124. Zhang Y, Qu X, Li C, Fan Y, Che X, Wang X, Cai Y, Hu X and Liu Y: miR-103/107 modulates multidrug resistance in human gastric carcinoma by downregulating Cav-1. Tumour Biol 36: 2277-2285, 2015.

125. Shen Q, Yao Q, Sun J, Feng L, Lu H, Ma Y, Liu L, Wang F, Li J, Yue Y, et al: Downregulation of histone deacetylase 1 by microRNA-520h contributes to the chemotherapeutic effect of doxorubicin. FEBS Lett 588: 184-191, 2014.

126. Chen J, Zhou C, Li J, Xiang X, Zhang L, Deng J and Xiong J: miR-21-5p confers doxorubicin resistance in gastric cancer cells by targeting PTEN and TIMP3. Int J Mol Med 41: 1855-1866, 2018.

127. Zou J and Xu Y: MicroRNA-140 inhibits cell proliferation in gastric cancer cell line HGC-27 by suppressing SOX4. Med Sci Monit 22: 2243-2252, 2016.

128. Pan Y, Ren F, Zhang W, Liu G, Yang D, Hu J, Feng K and Feng Y: Regulation of BGC-823 cell sensitivity to adriamycin via miRNA-135a-5p. Oncol Rep 32: 2549-2556, 2014

129. Wang F, Li T, Zhang B, Li H, Wu Q, Yang L, Nie Y, Wu K, Shi Y and Fan D: MicroRNA-19a/b regulates multidrug resistance in human gastric cancer cells by targeting PTEN. Biochem Biophys Res Commun 434: 688-694, 2013.

130. Zhou Z, Lin Z, He Y, Pang X, Wang Y, Ponnusamy M, Ao X Shan P, Tariq MA, Li P, et al: The long noncoding RNA D63785 regulates chemotherapy sensitivity in human gastric cancer by targeting miR-422a. Mol Ther Nucleic Acids 12: 405-419, 2018

131. Zhang J, Zhao B, Chen X, Wang Z, Xu H and Huang B: Silence of long noncoding RNA NEAT1 inhibits malignant biological behaviors and chemotherapy resistance in gastric cancer. Pathol Oncol Res 24: 109-113, 2018

132. Cao W, Wei W, Zhan Z, Xie D, Xie Y and Xiao Q: Regulation of drug resistance and metastasis of gastric cancer cells via the microRNA647-ANK2 axis. Int J Mol Med 41: 1958-1966, 2018 
133. Cao W, Wei W, Zhan Z, Xie Y and Xiao Q: MiR-1284 modulates multidrug resistance of gastric cancer cells by targeting EIF4A1. Oncol Rep 35: 2583-2591, 2016.

134.Zhu W, Zhu D, Lu S, Wang T, Wang J, Jiang B, Shu Y and Liu P. miR-497 modulates multidrug resistance of human cancer cell lines by targeting BCL2. Med Oncol 29: 384-391, 2012.

135.Zhu W, Shan X, Wang T, Shu Y and Liu P: miR-181b modulates multidrug resistance by targeting BCL2 in human cancer cell lines. Int J Cancer 127: 2520-2529, 2010.

136. Xia L, Zhang D, Du R, Pan Y, Zhao L, Sun S, Hong L, Liu J and Fan D: miR-15b and miR-16 modulate multidrug resistance by targeting BCL2 in human gastric cancer cells. Int J Cancer 123: 372-379, 2008.

137.Zhu W, Xu H, Zhu D, Zhi H, Wang T, Wang J, Jiang B, Shu Y and Liu P: miR-200bc/429 cluster modulates multidrug resistance of human cancer cell lines by targeting BCL2 and XIAP. Cancer Chemother Pharmacol 69: 723-731, 2012.

138. Yan LH, Chen ZN, Li-Li, Chen J, Wei WE, Mo XW, Qin YZ, Lin $Y$ and Chen JS: miR-135a promotes gastric cancer progression and resistance to oxaliplatin. Oncotarget 7: 70699-70714, 2016

139. Wu X, Zheng Y, Han B and Dong X: Long noncoding RNA BLACAT1 modulates ABCB1 to promote oxaliplatin resistance of gastric cancer via sponging miR-361. Biomed Pharmacother 99: 832-838, 2018.

140. Yared JA and Tkaczuk KH: Update on taxane development: New analogs and new formulations. Drug Des Devel Ther 6: 371-384, 2012.

141. Wu H, Huang M, Lu M, Zhu W, Shu Y, Cao P and Liu P: Regulation of microtubule-associated protein tau (MAPT) by miR-34c-5p determines the chemosensitivity of gastric cancer to paclitaxel. Cancer Chemother Pharmacol 71: 1159-1171, 2013.

142. Tian L, Zhao Z, Xie L and Zhu J: MiR-361-5p suppresses chemoresistance of gastric cancer cells by targeting FOXM1 via the PI3K/Akt/mTOR pathway. Oncotarget 9: 4886-4896, 2017.

143. Kang YK, Ryoo BY, Yoon S, Shen L, Lee J, Wei C, Zhou Y and Ryu MH: A Phase I study of cabazitaxel in patients with advanced gastric cancer who have failed prior chemotherapy (GASTANA). Cancer Chemother Pharmacol 75: 309-318, 2015.

144. Ju C, Wen Y, Zhang L, Wang Q, Xue L, Shen J and Zhang C: Neoadjuvant chemotherapy based on abraxane/human neutrophils cytopharmaceuticals with radiotherapy for gastric cancer. Small 15: e1804191, 2018.

145. Simón-Gracia L, Hunt H, Scodeller PD, Gaitzsch J, Braun GB Willmore AM, Ruoslahti E, Battaglia G and Teesalu T: Paclitaxel-loaded polymersomes for enhanced intraperitoneal chemotherapy. Mol Cancer Ther 15: 670-679, 2016.

146. Harada K, Mizrak Kaya D, Shimodaira Y and Ajani JA: Global chemotherapy development for gastric cancer. Gastric Cancer 20 (Suppl 1): 92-101, 2017.

147. Venturutti L, Cordo Russo RI, Rivas MA, Mercogliano MF, Izzo F, Oakley RH, Pereyra MG, De Martino M, Proietti CJ, Yankilevich P, et al: MiR-16 mediates trastuzumab and lapatinib response in ErbB-2-positive breast and gastric cancer via its novel targets CCNJ and FUBP1. Oncogene 35: 6189-6202, 2016.

148. Chen DS and Mellman I: Oncology meets immunology: The cancer-immunity cycle. Immunity 39: 1-10, 2013

149. Pardoll DM: The blockade of immune checkpoints in cancer immunotherapy. Nat Rev Cancer 12: 252-264, 2012.

150. Freeman GJ, Long AJ, Iwai Y, Bourque K, Chernova $T$, Nishimura H,FitzLJ, Malenkovich N, OkazakiT, Byrne MC, et al: Engagement of the PD-1 immunoinhibitory receptor by a novel B7 family member leads to negative regulation of lymphocyte activation. J Exp Med 192: 1027-1034, 2000.

151. Sharma P and Allison JP: The future of immune checkpoint therapy. Science 348: 56-61, 2015.

152. Abril-Rodriguez G and Ribas A: SnapShot: Immune checkpoint inhibitors. Cancer Cell 31: 848-848.e841, 2017.

153. Kamath SD, Kalyan A and Benson AB III: Pembrolizumab for the treatment of gastric cancer. Expert Rev Anticancer Ther 18: 1177-1187, 2018

154. Smolle MA, Calin HN, Pichler M and Calin GA: Noncoding RNAs and immune checkpoints-clinical implications as cancer therapeutics. FEBS J 284: 1952-1966, 2017.

155. Wei J, Nduom EK, Kong LY, Hashimoto Y, Xu S, Gabrusiewicz K, Ling X, Huang N, Qiao W, Zhou S, et al: MiR-138 exerts anti-glioma efficacy by targeting immune checkpoints. Neuro Oncol 18: 639-648, 2016.
156. Fujita Y, Yagishita S, Hagiwara K, Yoshioka Y, Kosaka N, Takeshita F, Fujiwara T, Tsuta K, Nokihara H, Tamura T, et al: The clinical relevance of the miR-197/CKS1B/STAT3-mediated PD-L1 network in chemoresistant non-small-cell lung cancer. Mol Ther 23: 717-727, 2015.

157. Bullock MD, Silva AM, Kanlikilicer-Unaldi P, Filant J, Rashed MH, Sood AK, Lopez-Berestein G and Calin GA: Exosomal non-coding RNAs: Diagnostic, prognostic and therapeutic applications in cancer. Noncoding RNA 1: 53-68, 2015.

158. Bullrich F, Fujii H, Calin G, Mabuchi H, Negrini M, Pekarsky Y, Rassenti L, Alder H, Reed JC, Keating MJ, et al: Characterization of the 13q14 tumor suppressor locus in CLL: Identification of ALT1, an alternative splice variant of the LEU2 gene. Cancer Res 61: 6640-6648, 2001

159. Bader AG, Brown D and Winkler M: The promise of microRNA replacement therapy. Cancer Res 70: 7027-7030, 2010.

160. Gandellini P, Profumo V, Folini M and Zaffaroni N: MicroRNAs as new therapeutic targets and tools in cancer. Expert Opin Ther Targets 15: 265-279, 2011 .

161. van der Ree MH, van der Meer AJ, van Nuenen AC, de Bruijne J, Ottosen S, Janssen HL, Kootstra NA and Reesink HW: Miravirsen dosing in chronic hepatitis $\mathrm{C}$ patients results in decreased microRNA-122 levels without affecting other microRNAs in plasma. Aliment Pharmacol Ther 43: 102-113, 2016.

162. Janssen HL, Reesink HW, Lawitz EJ, Zeuzem S, RodriguezTorres M, Patel K, van der Meer AJ, Patick AK, Chen A, Zhou Y, et al: Treatment of HCV infection by targeting microRNA. N Engl J Med 368: 1685-1694, 2013.

163. Mitchell PS, Parkin RK, Kroh EM, Fritz BR, Wyman SK, Pogosova-Agadjanyan EL, Peterson A, Noteboom J, O'Briant KC, Allen A, et al: Circulating microRNAs as stable blood-based markers for cancer detection. Proc Natl Acad Sci USA 105: 10513-10518, 2008.

164. Wang H, Wang L, Wu Z, Sun R, Jin H, Ma J, Liu L, Ling R, Yi J, Wang L, et al: Three dysregulated microRNAs in serum as novel biomarkers for gastric cancer screening. Med Oncol 31: 298, 2014.

165. Kim CH, Kim HK, Rettig RL, Kim J, Lee ET, Aprelikova O, Choi IJ, Munroe DJ and Green JE: miRNA signature associated with outcome of gastric cancer patients following chemotherapy. BMC Med Genomics 4: 79, 2011.

166. Dehghanzadeh R, Jadidi-Niaragh F, Gharibi T and Yousefi M: MicroRNA-induced drug resistance in gastric cancer. Biomed Pharmacother 74: 191-199, 2015

167. Baumann V and Winkler J: miRNA-based therapies: Strategies and delivery platforms for oligonucleotide and non-oligonucleotide agents. Future Med Chem 6: 1967-1984, 2014.

168. Boudreau RL, Martins I and Davidson BL: Artificial microRNAs as siRNA shuttles: Improved safety as compared to shRNAs in vitro and in vivo. Mol Ther 17: 169-175, 2009.

169. Safaei R, Larson BJ, Cheng TC, Gibson MA, Otani S, Naerdemann W and Howell SB: Abnormal lysosomal trafficking and enhanced exosomal export of cisplatin in drug-resistant human ovarian carcinoma cells. Mol Cancer Ther 4: 1595-1604, 2005.

170. Ciravolo V, Huber V, Ghedini GC, Venturelli E, Bianchi F, Campiglio M, Morelli D, Villa A, Della Mina P, Menard S, et al: Potential role of HER2-overexpressing exosomes in countering trastuzumab-based therapy. J Cell Physiol 227: 658-667, 2012.

171. Zhang HD, Jiang LH, Hou JC, Zhong SL, Zhu LP, Wang DD, Zhou SY, Yang SJ, Wang JY, Zhang Q, et al: Exosome: A novel mediator in drug resistance of cancer cells. Epigenomics 10: 1499-1509, 2018.

172. Shuwen H, Qing Z, Yan Z and Xi Y: Competitive endogenous RNA in colorectal cancer: A systematic review. Gene 645: 157-162, 2018.

173. Qu L, Ding J, Chen C, Wu ZJ, Liu B, Gao Y, Chen W, Liu F, Sun W, Li XF, et al: Exosome-transmitted lncARSR promotes sunitinib resistance in renal cancer by acting as a competing endogenous RNA. Cancer Cell 29: 653-668, 2016.

174. Wang D, Yang S, Wang H, Wang J, Zhang Q, Zhou S, He Y, Zhang H, Deng F, Xu H, et al: The progress of circular RNAs in various tumors. Am J Transl Res 10: 1571-1582, 2018.

175. Kun-Peng Z, Xiao-Long M and Chun-Lin Z: Overexpressed circPVT1, a potential new circular RNA biomarker, contributes to doxorubicin and cisplatin resistance of osteosarcoma cells by regulating ABCB1. Int J Biol Sci 14: 321-330, 2018.

This work is licensed under a Creative Commons Attribution-NonCommercial-NoDerivatives 4.0 International (CC BY-NC-ND 4.0) License. 